\title{
OPORTUNIDADES Y DESAFÍOS PARA CHILE DE LA APERTURA ECONÓMICA EN CHINA*
}

\author{
Sebastián Claro
}

En este trabajo se discuten las oportunidades y desafíos que enfrenta Chile debido a la apertura y al crecimiento experimentado por China a partir de 1978. Para ello se identifica el grado de competencia que representan las exportaciones chinas para los productores chilenos en distintas industrias, así como los mercados en los cuales las oportunidades para los productores chilenos son mayores. Adicionalmente, se entrega un detallado análisis de las acciones comerciales que ha realizado Chile en los últimos 25 años para aprovechar o protegerse de la mayor penetración china en los mercados mundiales. El trabajo concluye con una discusión de dos de los principales temas en las relaciones comerciales actuales con China: su rol en el mercado mundial del cobre y elementos para tomar en cuenta en un posible tratado de libre comercio.

Sebastián Claro. Ingeniero Comercial y Magíster en Economía, Pontificia Universidad Católica de Chile. M. A. y Ph. D., University of California, Los Ángeles. Profesor Instituto de Economía Pontificia Universidad Católica de Chile.

* Este artículo está basado en un trabajo encargado por el Banco Interamericano de Desarrollo como parte de un proyecto para analizar el impacto de la apertura de China en América Latina. Agradezco los comentarios de Antoni Estevardeordal, Michael Devlin, Peter Schott y de los participantes en un seminario del BID en Washington. Agradezco también la colaboración de Juan Eduardo Chackiel y Alejandra Rozas, de la Comisión Nacional de Distorsiones de Precios; de Hernán Gutiérrez y Roberto Paiva, de la Dirección Económica de la Cancillería, Direcon; de Javier Plá, de Copihue; Sebastián Gil y Gonzalo Sánchez, de Antofagasta Minerals. Finalmente, agradezco el eficiente trabajo de José Miguel Ossa en la búsqueda y análisis de los datos. 


\section{Introducción}

\section{L}

importancia económica de China en el mundo ha crecido fuertemente en los últimos 25 años $^{1}$. El comercio total de China -medido como exportaciones más importaciones- creció de US\$ 38 billones en 1980 a US\$ 510 billones el año 2002. Este aumento en los flujos comerciales estuvo acompañado por un fuerte incremento en el producto interno bruto, que pasó de 215,8 a 1.132,0 billones de dólares en el mismo período ${ }^{2}$. El incremento de la penetración de China en los mercados mundiales es evidente a partir de 1990, cuando los flujos de inversión extranjera aumentaron significativamente. En 1990, la inversión extranjera en China fue de 2,66 billones de dólares, cifra que aumentó a 37,36 billones en 2002 .

Los efectos de este crecimiento en terceros países y en diversos mercados han sido objeto de fuerte debate en los últimos años ${ }^{3}$. Especial énfasis se ha puesto en la discusión del efecto en salarios y en producción manufacturera del surgimiento de una potencia con más de 1.250 millones de habitantes y en la posibilidad de que China absorba gran parte de la producción manufacturera mundial, en desmedro de actuales exportadores de productos industriales. Un primer objetivo de este trabajo es discutir las oportunidades y desafíos que representa para Chile la apertura económica en China desde un punto de vista comercial. Para ello se describen los mecanismos comerciales a través de los cuales la apertura en China puede afectar a Chile y las acciones que Chile ha realizado para enfrentar los riesgos y oportunidades asociados a la apertura en China.

La primera parte del trabajo compara la estructura comercial de Chile y la de China, de manera de identificar los sectores productivos más afectados por la competencia china y los sectores más beneficiados por el crecimiento en la demanda en China. La discusión de los sectores favorecidos y perjudicados con la apertura en China no tiene una directa connotación en bienestar, ya que aun cuando los productores de un bien pueden verse negativamente afectados por la fuerte competencia china en terceros mercados o por un fuerte aumento en las importaciones, los consumidores nacionales pueden verse altamente beneficiados. El foco del trabajo es identificar mercados en los cuales la apertura en China es relevante para Chile, sin entrar en la discusión del impacto en bienestar agregado.

${ }^{1}$ Claro (2003) presenta un detallado análisis de las reformas económicas en China a partir de 1978. Ver también Chow (2002).

${ }^{2}$ World Development Indicators, 2003.

${ }^{3}$ Ver, por ejemplo, Naughton (1996) y Freeman (1995). 
La segunda parte analiza las acciones comerciales emprendidas por Chile para aprovechar o compensar los impactos sectoriales de la mayor penetración china en los mercados mundiales. Se presenta un análisis detallado tanto de las acciones comerciales iniciadas por Chile en contra de productos chinos, así como de la posición de Chile en el proceso de incorporación de China a la Organización Mundial de Comercio (OMC).

Finalmente, el trabajo analiza dos temas importantes en las relaciones comerciales con China en el futuro. Por una parte se analizan las implicancias del crecimiento de China en el mercado mundial del cobre y las consecuencias que de ahí se derivan para Chile. Por otra parte, se discuten algunos temas importantes de tener en cuenta en un tratado de libre comercio (TLC) con China.

\section{Relaciones comerciales Chile-China}

El comercio bilateral de Chile y China ha aumentado fuertemente en las últimas dos décadas —especialmente a partir de 1990—. El Cuadro $\mathrm{N}^{\circ} 1$ muestra el comercio bilateral de Chile y China así como el comercio total de Chile entre 1980 y 2003. En 1980, China representaba el 1,5\% de las exportaciones totales chilenas y $0,5 \%$ del total de importaciones, mientras que estas cifras eran $9,1 \%$ y 7,1\%, respectivamente, en el año 2003 .

La participación de China en el comercio chileno se aprecia en el Gráfico $\mathrm{N}^{\circ} 1$. Tres elementos son interesantes de destacar. Primero, la relación comercial entre Chile y China es balanceada, ya que no existe déficit ni superávit bilateral significativo en alguna dirección. Aun cuando desde el punto de vista económico el análisis de la balanza comercial bilateral no es relevante, sí lo es desde un punto de vista político; la existencia de un déficit comercial bilateral importante puede acarrear presiones proteccionistas en contra de los productos del socio comercial. Esto es claro en el caso de Estados Unidos, donde el déficit bilateral de más de 100 billones de dólares en 2002 ha dado paso a importantes presiones políticas para tomar acciones comerciales en contra de China ${ }^{4}$.

Segundo, la penetración de importaciones desde China es evidente a partir de 1990. Como veremos en detalle más adelante, esta penetración se explica por el fuerte incremento de las importaciones de vestuario, telas,

${ }^{4}$ De acuerdo a Office of Trade and Economic Analysis, del Bureau of Economic Analysis, el año 2002 las exportaciones de Estados Unidos a China fueron por 22,16 billones de dólares, mientras que las exportaciones de China a EE.UU. fueron por 125,2 billones de dólares. 
CUADRO N$^{\circ} 1: \quad$ EXPORTACIONES E IMPORTACIONES CHILENAS: 1980-2003

(Millones de dólares, FOB)

\begin{tabular}{|c|c|c|c|c|}
\hline \multirow[t]{2}{*}{ Año } & \multicolumn{2}{|c|}{ Total } & \multicolumn{2}{|c|}{ China* } \\
\hline & Exp. & Imp. & Exp. & Imp. \\
\hline 1980 & 4.671 & 5.489 & 105 & 21 \\
\hline 1981 & 3.952 & 6.775 & 61 & 35 \\
\hline 1982 & 3.710 & 3.831 & 62 & 22 \\
\hline 1983 & 3.836 & 2.969 & 94 & 10 \\
\hline 1984 & 3.657 & 3.481 & 125 & 12 \\
\hline 1985 & 3.823 & 3.007 & 125 & 24 \\
\hline 1986 & 4.222 & 3.157 & 100 & 21 \\
\hline 1987 & 5.102 & 4.023 & 79 & 57 \\
\hline 1988 & 7.048 & 4.924 & 99 & 55 \\
\hline 1989 & 8.190 & 6.734 & 104 & 48 \\
\hline 1990 & 8.631 & 7.347 & 31 & 57 \\
\hline 1991 & 9.048 & 7.760 & 79 & 95 \\
\hline 1992 & 10.124 & 9.756 & 281 & 147 \\
\hline 1993 & 9.415 & 10.869 & 184 & 213 \\
\hline 1994 & 11.643 & 11.501 & 133 & 281 \\
\hline 1995 & 16.445 & 15.348 & 288 & 390 \\
\hline 1996 & 15.396 & 17.353 & 354 & 515 \\
\hline 1997 & 17.888 & 20.763 & 579 & 721 \\
\hline 1998 & 16.396 & 19.835 & 586 & 760 \\
\hline 1999 & 17.170 & 15.805 & 567 & 710 \\
\hline 2000 & 19.206 & 18.445 & 966 & 999 \\
\hline 2001 & 18.394 & 17.784 & 1.070 & 1.053 \\
\hline 2002 & 18.421 & 17.169 & 1.270 & 1.172 \\
\hline 2003 & 21.255 & 19.326 & 1.941 & 1.367 \\
\hline
\end{tabular}

* Incluye Hong Kong desde 1997.

Fuente: Banco Central de Chile.

juguetes y artículos electrónicos. Debido a que la apertura comercial en Chile comenzó a mediados de los 1970, es razonable pensar que las importaciones desde China han desplazado a las importaciones de otros países más que a la producción doméstica. Finalmente, llama la atención el fuerte incremento en las exportaciones hacia China a partir de 1999. Este incremento se explica básicamente por la fuerte demanda de cobre desde China. Este tema es abordado en detalle más adelante.

Aun cuando se pueden extraer algunas conclusiones generales al observar la evolución agregada del comercio, se requiere un análisis más detallado de cuáles son las industrias que dominan la expansión de las exportaciones y de las importaciones, de manera de identificar los sectores 
GRÁFICO N ${ }^{\circ}$ 1: $\quad$ PARTICIPACIÓN DE CHINA EN LAS IMPORTACIONES Y EXPORTACIONES DE CHILE

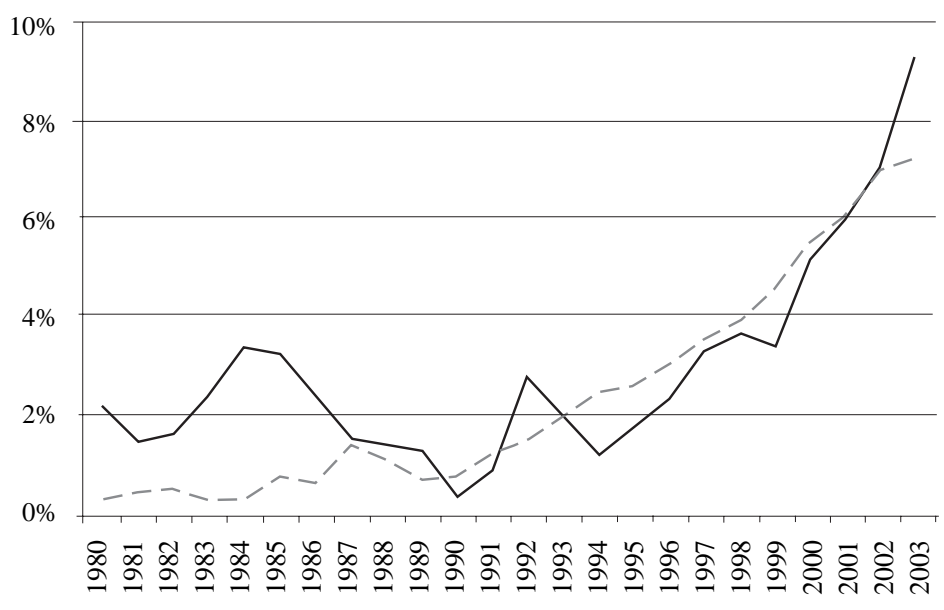

— Exportaciones --- Importaciones

más beneficiados y perjudicados con la apertura en China. En particular, se requiere identificar industrias en las cuales los productores chilenos compiten con los productores chinos, tanto en mercados internacionales como en el mercado chileno. En ambos casos la penetración china puede perjudicar la posición de los productores nacionales. Además, se deben identificar las industrias en las cuales la apertura en China presenta oportunidades para los productores chilenos.

\subsection{Competencia en terceros mercados}

Una metodología muy usada para comparar la estructura comercial de dos países es computar el Índice de Similitud de Exportaciones — Export Similarity Index (ESI) — entre dos países, que mide cuán parecida es la participación de distintos productos en las exportaciones totales de un

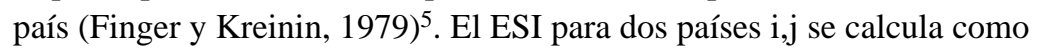

$$
\mathrm{ESI}_{\mathrm{ij}}=100 * \Sigma_{\mathrm{c}} \min \left(\mathrm{X}_{\mathrm{c}}^{\mathrm{i}}, \mathrm{X}_{\mathrm{c}}^{\mathrm{j}}\right)
$$

\footnotetext{
${ }^{5}$ Contreras y Meller (2002) muestran indicadores similares.
} 
donde $\mathrm{X}_{\mathrm{c}}^{\mathrm{i}}$ representa la participación de las exportaciones brutas del bien c en las exportaciones totales del país i. El índice varía entre 100 -igual composición de las exportaciones en los dos países- y 0 —ninguna similitud en las exportaciones-. Es evidente que el ESI depende del nivel de agregación. La posibilidad de que dos países sean exportadores del mismo bien en un nivel de desagregación muy alto es baja, mientras que las estadísticas más agregadas entregan por construcción mayores grados de similitud. En el límite, las exportaciones agregadas implican un ESI de 100 .

Debido a la escasez de datos desagregados de exportaciones totales de Chile y China, el ESI de Chile y China se calcula tomando en cuenta las exportaciones totales hacia Estados Unidos el año 2002. El Cuadro $\mathrm{N}^{\circ} 2$ muestra las exportaciones totales agrupadas en categoría de dos dígitos del sistema armonizado (HS) ${ }^{6}$. Las columnas 6 y 7 muestran la participación de cada categoría en las exportaciones totales de cada país hacia Estados Unidos, y las columnas 8 y 9 muestran la penetración de cada país en las importaciones totales de Estados Unidos en cada categoría. Por ejemplo, las exportaciones de Chile hacia Estados Unidos de pescado y crustáceos (HS 03) fueron US\$ 614 millones, que representa el 14,9\% de las exportaciones chilenas a EE.UU. y el 7,3\% de las importaciones totales de Estados Unidos de pescados y crustáceos.

Las exportaciones chilenas están concentradas en frutas (08), madera y manufacturas de madera (44), pescado y crustáceos (03), cobre y minerales metalíferos $(74,26)$, productos químicos orgánicos e inorgánicos $(29,28)$ y bebidas (22). Estas industrias representan más del $78 \%$ de las exportaciones totales. Las principales exportaciones de China a Estados Unidos son prendas de vestir (62), manufacturas de cuero (42), calzado (64), plástico y juguetes $(39,95)$, reactores nucleares y máquinas y material eléctrico $(84,85)$ y muebles $(94)$. La única industria que representa una "alta" participación en las exportaciones de Chile y China son los muebles (94), con una participación de $1,4 \%$ y $8,5 \%$ respectivamente.

El Cuadro $\mathrm{N}^{\circ} 2$ revela que las estructuras de exportaciones de Chile y China son muy distintas, lo que se refleja en un bajo ESI. Calculado a nivel de dos dígitos HS, el ESI es 10,9; 5 a 5 dígitos SITC $^{7}$; y 3 a 8 y 10 dígitos del sistema armonizado. Estos valores se comparan con un ESI

\footnotetext{
${ }^{6}$ El sistema armonizado de clasificación de comercio se divide en 99 secciones (2 dígitos) agrupadas en 22 capítulos ( 1 dígito). Cada sección se desagrega en productos identificados hasta 10 dígitos.

${ }^{7}$ SITC se refiere a Standard Industry Trade Classification, que es otra clasificación para agrupar datos de comercio internacional.
} 
entre México y China de 21 y Brasil y China de 12 usando datos a 10 dígitos HS (ver Schott, 2004) ${ }^{8}$. Esto podría interpretarse como que China no representa competencia importante en los mercados internacionales -en particular en Estados Unidos- para los exportadores Chilenos.

Sin embargo, el ESI es claramente una medida incompleta del grado de competencia en que un país enfrenta a otro. Los exportadores chinos representan competencia para los exportadores chilenos en la medida en que China sea un exportador importante en los mercados internacionales de productos que Chile exporta, independientemente de si ese producto representa o no una alta proporción de las exportaciones chinas. Más aún, hay productos que pertenecen a categorías distintas pero que son sustitutos en consumo o pertenecen a la misma cadena de producción, por lo que hay espacio para competencia indirecta aun cuando dos países exporten una combinación (mix) de productos —a un nivel de desagregación altodistintos.

El Cuadro $\mathrm{N}^{\circ} 3$ muestra las principales exportaciones chilenas a Estados Unidos clasificadas en 2 dígitos HS, las exportaciones de China a Estados Unidos y la participación de cada país en las importaciones totales desde Estados Unidos en cada categoría. Por ejemplo, China es un importante exportador de pescado y crustáceos (HS 03) a Estados Unidos —un 16,2\% de las importaciones de Estados Unidos provienen de China-, lo que sugiere que las exportaciones chinas representan competencia para los productores chilenos, aun cuando tales exportaciones representen una participación baja en las exportaciones totales chinas. Al concentrarse en los principales productos de exportación chilenos, el Cuadro $\mathrm{N}^{\circ} 3$ se centra en las industrias donde la competencia podría tener alguna relevancia a nivel agregado, pero no se descarta que en productos que representan una muy baja participación en las exportaciones chilenas exista importante competencia de exportadores chinos.

De acuerdo al Cuadro $\mathrm{N}^{\circ} 3$, las industrias en las cuales la competencia china podría ser relevante son pescados y crustáceos; preparaciones de hortalizas y frutas; productos químicos orgánicos e inorgánicos; piedras preciosas y sal; madera y manufacturas de madera, y muebles. En estas industrias, la penetración de productos chinos en las importaciones estadounidenses es mayor que la penetración chilena9 9

Un análisis más detallado (4 dígitos HS) muestra resultados interesantes. En las industrias de productos químicos orgánicos e inorgánicos; y

${ }^{8}$ El año 2001, Chile estaba en el lugar 12 entre 20 países, de acuerdo con su ESI con China (Schott, 2004).

${ }^{9}$ Éste es el criterio para definir las industrias a nivel de 2 dígitos HS, respecto a las cuales se realiza un análisis más detallado. 


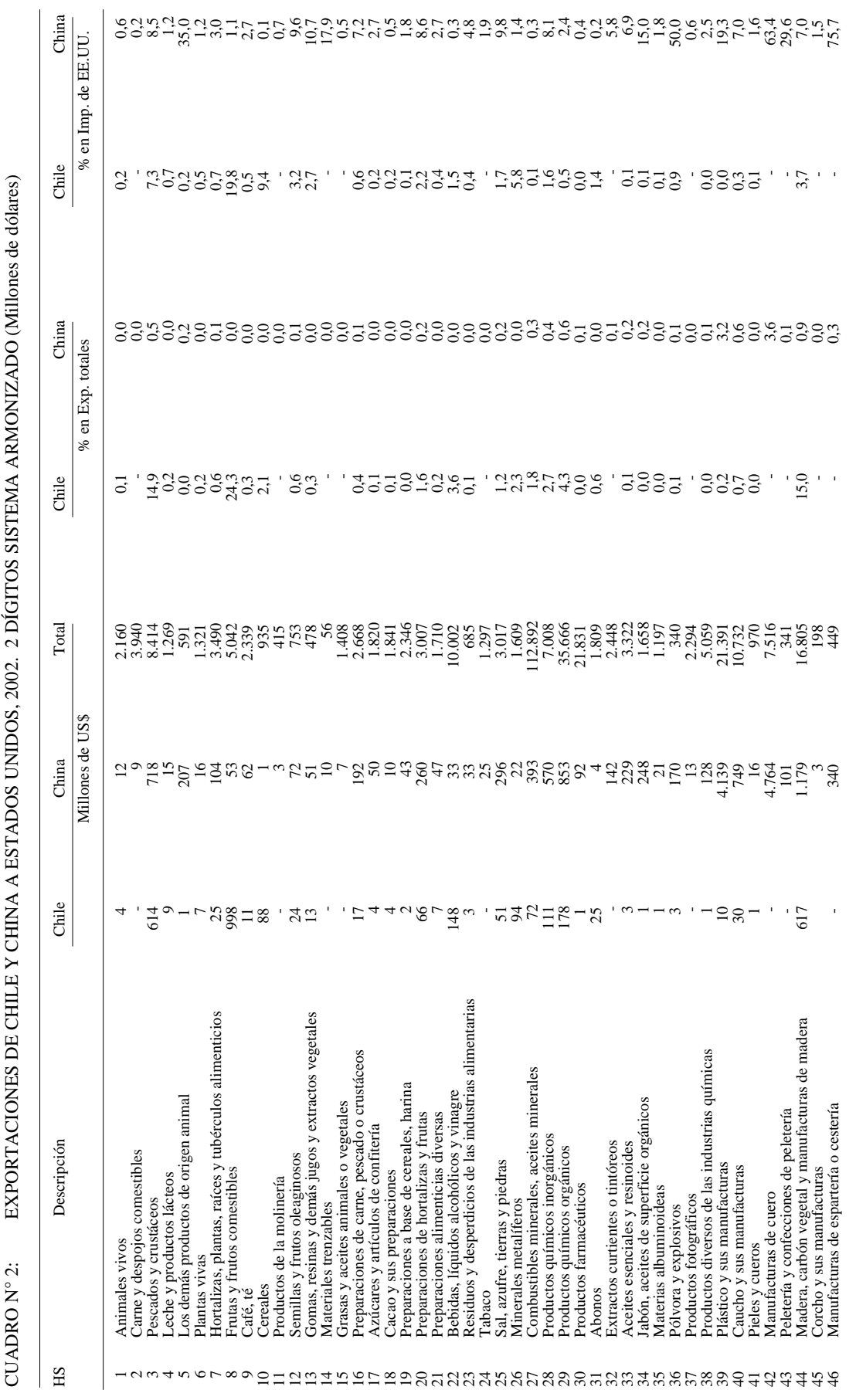




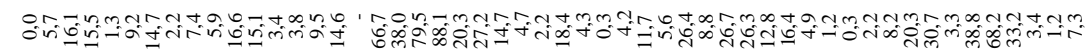

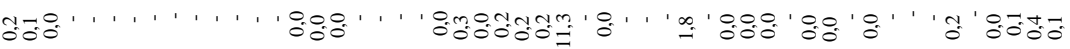

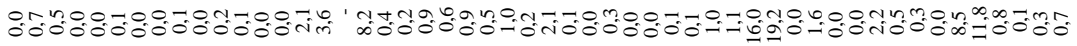

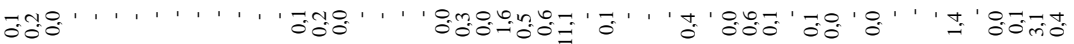

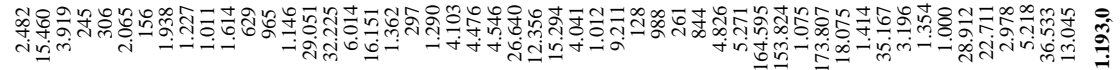

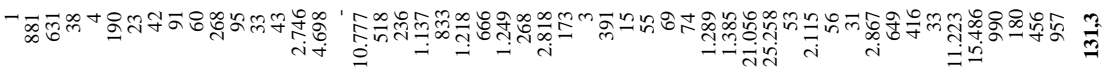

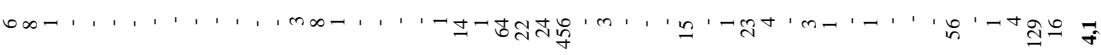

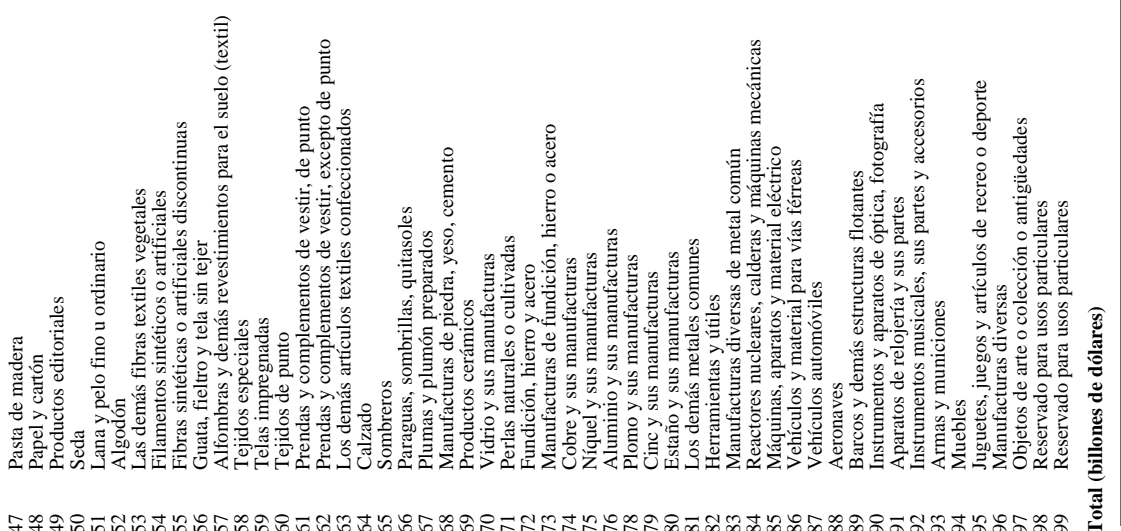


CUADRO N ${ }^{\circ}$ 3: $\quad$ EXPORTACIONES DE CHILE Y CHINA A EE. UU., 2002

INDUSTRIAS SELECCIONADAS

\begin{tabular}{|c|c|c|c|c|c|}
\hline \multirow[t]{2}{*}{ HS } & \multirow[t]{2}{*}{ Descripción } & \multicolumn{2}{|c|}{$\begin{array}{c}\text { Exportaciones } \\
\text { a EE. UU. } \\
\text { (Millones de US\$) }\end{array}$} & \multicolumn{2}{|c|}{$\begin{array}{c}\text { Participación } \\
\text { en importaciones } \\
\text { de EE. UU. (\%) }\end{array}$} \\
\hline & & Chile & China & Chile & China \\
\hline 8 & Frutas y frutos comestibles & 998 & 53 & 19,8 & 1,1 \\
\hline 44 & Madera, carbón vegetal y manufacturas de madera & 617 & 1.179 & 3,7 & 7,0 \\
\hline 3 & Pescados y crustáceos & 614 & 718 & 7,3 & 8,5 \\
\hline 74 & Cobre y sus manufacturas & 456 & 173 & 11,3 & 4,3 \\
\hline & Productos químicos orgánicos & 178 & 853 & 0,5 & 2,4 \\
\hline & Bebidas, líquidos alcohólicos y vinagre & 148 & 33 & 1,5 & 0,3 \\
\hline & Reservado para usos particulares & 129 & 456 & 0,4 & 1,2 \\
\hline & Productos químicos inorgánicos & 111 & 570 & 1,6 & 8,1 \\
\hline & Minerales metalíferos & 94 & 22 & 5,8 & 1,4 \\
\hline 10 & Cereales & 88 & 1 & 9,4 & 0,1 \\
\hline & Combustibles minerales, aceites minerales & 72 & 393 & 0,1 & 0,3 \\
\hline & Preparaciones de hortalizas y frutas & 66 & 260 & 2,2 & 8,6 \\
\hline & Perlas naturales o cultivadas & 64 & 1.249 & 0,2 & 4,7 \\
\hline 94 & Muebles & 56 & 11.223 & 0,2 & 38,8 \\
\hline & Sal, azufre, tierras y piedras & 51 & 296 & 1,7 & 9,8 \\
\hline
\end{tabular}

Fuente: U.S. International Trade Commission, www.dataweb.usitc.gov

piedras preciosas y sal, las exportaciones chilenas son muy distintas de las exportaciones chinas, por lo que no existen indicios de mayor competencia. Por ejemplo, las exportaciones chilenas de flúor y cloro (HS 2801) por US\$ 54 millones no compiten con las exportaciones chinas de elementos químicos radiactivos (HS 2844) por US\$ 99 millones. Igualmente, las exportaciones chilenas de sal (HS 2501) por US\$ 49 millones no compiten con las exportaciones chinas de cemento Portland (HS 2523) o de feldespato (HS 2529) por US\$ 89 millones y US\$ 44 millones, respectivamente. El detalle de las exportaciones en estas industrias no se presenta por razones de espacio.

Los Cuadros Nos. 4.1 a 4.4 muestran en detalle las exportaciones de Chile y China a EE.UU. en las industrias de pescado y crustáceos (HS 03), preparaciones de hortalizas y frutas (HS 20), madera y manufacturas de madera (HS 44) y muebles (HS 94). Las columnas 6 y 7 muestran las exportaciones de Estados Unidos en cada categoría a Chile y China, de manera de poder enfocarse en las exportaciones netas.

Chile y China tienen una alta penetración en el mercado de filetes de pescado (HS 0304), 24,6\% y 16,2\%, respectivamente. Una mirada más desagregada (10 dígitos HS) muestra que las principales exportaciones 
CUADRO N 4.1: HS 03: PESCADOS Y CRUSTÁCEOS

(Millones de dólares)

\begin{tabular}{|c|c|c|c|c|c|c|}
\hline \multirow[t]{2}{*}{ HS } & \multirow[t]{2}{*}{ Descripción } & \multicolumn{3}{|c|}{ Imp. de EE. UU. 2002} & \multicolumn{2}{|c|}{ Exp. de EE. UU. 2002} \\
\hline & & Chile & China & Total & Chile & China \\
\hline 301 & Peces o pescado vivo & & 1 & 67 & 0 & 0 \\
\hline 302 & Los demás pescados vivos & 41 & 3 & 955 & 0 & 12 \\
\hline 303 & Pescado congelado, excepto filetes & 12 & 40 & 367 & 0 & 56 \\
\hline 304 & Filete y demás carne de pescado & 534 & 352 & 2.175 & 0 & 4 \\
\hline 305 & Pescado seco, salado o en salmuera & 13 & 21 & 162 & 0 & 5 \\
\hline & Crustáceos & 9 & 226 & 4.238 & 0 & 17 \\
\hline 307 & Moluscos & 5 & 72 & 450 & 0 & 20 \\
\hline Tota & & 614 & 715 & 8.414 & $\mathbf{0}$ & 114 \\
\hline
\end{tabular}

Fuente: U.S. International Trade Commission, www.dataweb.usitc.gov

CUADRO N ${ }^{\circ}$ 4.2: $\quad$ HS 20: PREPARACIONES DE HORTALIZAS Y FRUTAS

(Millones de dólares)

\begin{tabular}{|c|c|c|c|c|c|c|}
\hline \multirow[t]{2}{*}{ HS } & \multirow[t]{2}{*}{ Descripción } & \multicolumn{3}{|c|}{ Imp. de EE.UU. 2002} & \multicolumn{2}{|c|}{ Exp. de EE.UU. 2002} \\
\hline & & Chile & China & Total & Chile & China \\
\hline 2001 & $\begin{array}{l}\text { Vegetales y frutas preparadas y } \\
\text { conservadas en vinagre o ácido acético }\end{array}$ & 0 & 3 & 204 & 0 & 0 \\
\hline 2002 & Tomates preparados o preservados & 1 & 3 & 24 & 0 & 0 \\
\hline 2003 & Setas y demás hongos & 0 & 18 & 110 & 0 & 0 \\
\hline 2004 & $\begin{array}{l}\text { Las demás hortalizas preparadas } \\
\text { y congeladas }\end{array}$ & 0 & & 427 & 0 & 24 \\
\hline 2005 & Guisantes & 4 & 37 & 560 & 1 & 4 \\
\hline 2006 & $\begin{array}{l}\text { Hortalizas y frutos confitados } \\
\text { con azúcar }\end{array}$ & 0 & 1 & 18 & 0 & 0 \\
\hline 2007 & Confituras, jaleas y mermeladas & 1 & 0 & 61 & 0 & 0 \\
\hline 2008 & $\begin{array}{l}\text { Frutas y otros frutos conservados } \\
\text { de otro modo }\end{array}$ & 0 & 133 & 854 & 1 & 9 \\
\hline 2009 & Jugos de frutas & 60 & 64 & 749 & 0 & 5 \\
\hline Total & & 66 & 259 & 3.007 & 2 & 42 \\
\hline
\end{tabular}

Fuente: U.S International Trade Commission, www.dataweb.usitc.gov 
CUADRO $\mathrm{N}^{\circ}$ 4.3: $\quad$ HS 44: MADERA Y MANUFACTURAS DE MADERA

(Millones de dólares)

\begin{tabular}{|c|c|c|c|c|c|c|}
\hline \multirow[t]{2}{*}{ HS } & \multirow[t]{2}{*}{ Descripción } & \multicolumn{3}{|c|}{ Imp. de EE. UU. 2002} & \multicolumn{2}{|c|}{ Exp. de EE. UU. 2002} \\
\hline & & Chile & China & Total & Chile & China \\
\hline 4401 & $\begin{array}{l}\text { Aserrín, desperdicios y desechos } \\
\text { de madera }\end{array}$ & 0 & 0 & 90 & 0 & 2 \\
\hline 4402 & Carbón vegetal & 0 & 1 & 9 & 0 & 0 \\
\hline 4403 & Madera en bruto & 1 & 0 & 262 & 0 & 63 \\
\hline 4404 & Flejes de madera & 0 & 1 & 10 & 0 & 0 \\
\hline 4405 & Lana y harina de madera & 0 & 0 & 1 & 0 & 0 \\
\hline 4406 & $\begin{array}{l}\text { Durmientes de madera para vías } \\
\text { férreas u otros }\end{array}$ & 0 & 0 & 23 & 0 & 0 \\
\hline 4407 & Madera aserrada & 197 & 2 & 7.075 & 0 & 106 \\
\hline 4408 & Hojas para chapado o contrachapado & 5 & 6 & 473 & 1 & 35 \\
\hline 4409 & Madera perfilada & 209 & 78 & 998 & 1 & 4 \\
\hline 4410 & Tableros de partículas & 1 & 0 & 1.366 & 0 & 3 \\
\hline 4411 & Tableros de fibra de madera & 65 & 1 & 801 & 0 & 4 \\
\hline 4412 & Madera chapada o contrachapada & 39 & 120 & 1.390 & 0 & 0 \\
\hline 4413 & Madera densificada en bloques & 0 & 0 & 3 & 0 & 0 \\
\hline 4414 & Marcos de madera para cuadros & 1 & 200 & 427 & 0 & 0 \\
\hline 4415 & Cajones, cajas y otros & 2 & 4 & 166 & 0 & 0 \\
\hline 4416 & Barriles, tinas y cubas & 1 & 0 & 147 & 3 & 1 \\
\hline 4417 & $\begin{array}{l}\text { Herramientas, monturas y mangos } \\
\text { de herramientas }\end{array}$ & 5 & 3 & 45 & 0 & 2 \\
\hline 4418 & $\begin{array}{l}\text { Obras y piezas de carpintería para } \\
\text { construcciones }\end{array}$ & 82 & 54 & 1.837 & 0 & 2 \\
\hline 4419 & Artículos de mesa o de cocina & 0 & 41 & 99 & 0 & 0 \\
\hline 4420 & Marquetería y taracera & 0 & 415 & 560 & 0 & 0 \\
\hline 4421 & Las demás manufacturas de madera & 9 & 251 & 1.022 & 2 & 3 \\
\hline Total & & 617 & 1.177 & 16.804 & 7 & 225 \\
\hline
\end{tabular}

Fuente: U. S. International Trade Commission, www.dataweb.usitc.gov

CUADRO N ${ }^{\circ} .4: \quad$ HS 94: MUEBLES

(Millones de dólares)

\begin{tabular}{|c|c|c|c|c|c|c|}
\hline \multirow[t]{2}{*}{ HS } & \multirow[t]{2}{*}{ Descripción } & \multicolumn{3}{|c|}{ Imp. de EE. UU. 2002} & \multicolumn{2}{|c|}{ Exp. de EE. UU. 2002} \\
\hline & & Chile & China & Total & Chile & China \\
\hline 9401 & $\begin{array}{l}\text { Asientos, excepto los incluidos en } \\
\text { categoría } 9402\end{array}$ & 1 & 2.492 & 9.670 & 2 & 39 \\
\hline 9402 & $\begin{array}{l}\text { Mobiliario para medicina, cirugía, } \\
\text { odontología y veterinaria }\end{array}$ & 0 & 20 & 207 & 1 & 6 \\
\hline 9403 & $\begin{array}{l}\text { Muebles de madera del tipo utilizado } \\
\text { en cocinas }\end{array}$ & 55 & 4.932 & 12.739 & 5 & 17 \\
\hline 9404 & Somieres y artículos de cama & 0 & 527 & 966 & 1 & 0 \\
\hline 9405 & Aparatos de alumbrado y sus partes & 0 & 3.242 & 4.975 & 2 & 13 \\
\hline 9406 & Construcciones prefabricadas & 0 & 10 & 356 & 1 & 6 \\
\hline Total & & 56 & 11.223 & 28.913 & 12 & 81 \\
\hline
\end{tabular}

Fuente: U.S. International Trade Commission, www.dataweb.usitc.gov 
chilenas son salmón atlántico (HS 0304.104093), por US\$ 392 millones; filetes de trucha congelados (HS 0304.206006) por US\$ 83,4 millones; otros filetes congelados (HS 0304.2060096) por US\$19,1 millones, y pescado serrano (HS 0304.206093) por US\$ 11,3 millones, mientras que las principales exportaciones chinas son gado de Alaska (HS 0304.203065 y 0304.202044) por US\$131,3 millones, filetes de bacalao (HS 0304.203035) por US\$ 51,2 millones, filetes de lenguado (HS 0304.206057) por US\$ 24,4 millones y filetes de tilapia (HS 0304.206042) por US\$ 22 millones. Una discusión respecto del grado de sustitución en consumo entre el salmón Atlántico y el gado de Alaska va más allá de los objetivos de este trabajo. Sin embargo, es evidente que existe cierto grado de competencia indirecta en el mercado de pescado.

La competencia en preparaciones de frutas y vegetales es más evidente. Las exportaciones chilenas de jugo de manzana (HS 2009.7100 y 2009.7900) por US\$ 34 millones compiten directamente con las exportaciones chinas de los mismos productos por US\$ 51 millones. El análisis a 10 dígitos muestra que ambos países son importantes exportadores de concentrado de jugos, congelado y no congelado.

El análisis de la industria de la madera y artículos de madera revela elementos interesantes. Chile es un exportador neto de madera -especialmente categorías HS 4407 y 4409-, mientras que China es un importador neto de madera, no sólo desde Estados Unidos sino principalmente desde Rusia, Indonesia y Malasia. El año 2002, China importó US\$ 4,2 billones de madera y manufacturas de madera (HS 44) ${ }^{10}$, mientras que las exportaciones fueron por US $\$ 2,8$ billones $^{11}$. Este patrón es claro en el comercio bilateral de China con Estados Unidos, ya que China es un importador de madera y exportador de productos de madera. Este flujo importante de comercio intraindustrial se explica porque la categoría HS 44 incluye madera en sus distintas formas y artículos de madera — como marcos, cajas, barriles y herramientas-. Así, es claro que China importa madera para consumo doméstico y como insumo para la producción de artículos de madera, que son intensivos en mano de obra. De igual manera, la madera es un importante componente en muebles, donde China es el principal exportador mundial. El año 2002, las exportaciones de muebles de madera

${ }^{10}$ Las importaciones de madera en bruto (HS 4403) el año 2002 fueron por US\$ 2,14 billones, y las importaciones de madera aserrada fueron por US\$1,16 billones. Véase: USDA Foreign Agricultural Service: GAIN 2003 Annual Report on People's Republic of China "Solid Wood Products". Unidos $(25 \%)$.

${ }^{11}$ Los principales destinos de las exportaciones chinas son Japón (32\%) y Estados 
CUADRO N ${ }^{\circ}$ 4.5: $\quad$ HS 48: PAPEL Y CARTÓN

(Millones de dólares)

\begin{tabular}{|c|c|c|c|c|c|c|}
\hline \multirow[t]{2}{*}{ HS } & \multirow[t]{2}{*}{ Descripción } & \multicolumn{3}{|c|}{ Imp. de EE. UU. 2002} & \multicolumn{2}{|c|}{ Exp. de EE. UU. 2002} \\
\hline & & Chile & China & Total & Chile & China \\
\hline 4801 & Papel prensa en bobinas & 6,5 & 0,1 & 3.214 & 0 & 0 \\
\hline 4802 & $\begin{array}{l}\text { Papel y cartón, sin estucar ni } \\
\text { recubrir }\end{array}$ & 0 & 9,8 & 3.090 & 2 & 15 \\
\hline 4803 & $\begin{array}{l}\text { Papel del tipo utilizado para } \\
\text { papel higiénico }\end{array}$ & 0 & 4,9 & 231 & 1 & 2 \\
\hline 4804 & Papel y cartón kraft & 0,4 & 13,3 & 632 & 2 & 128 \\
\hline 4805 & $\begin{array}{l}\text { Los demás papeles y cartones } \\
\text { sin estucar ni recubrir }\end{array}$ & 0 & 1,1 & 422 & 1 & 5 \\
\hline 4806 & Papel y cartón sulfurizados & 0 & 0,4 & 73 & 0 & 0 \\
\hline 4807 & $\begin{array}{l}\text { Papel y cartón obtenidos por } \\
\text { pegado de hojas planas }\end{array}$ & 0 & 0,1 & 26 & 0 & 0 \\
\hline 4808 & Papel y cartón corrugados & 0 & 4,1 & 38 & 0 & 7 \\
\hline 4809 & Papel carbón y papel autocopia & 0 & 0,5 & 61 & 2 & 0 \\
\hline 4810 & Papel multicapas & 0,3 & 38,8 & 2.381 & 4 & 124 \\
\hline 4811 & Papel y cartón recubiertos o estucados & 0 & 12,6 & 1.016 & 6 & 53 \\
\hline 4812 & $\begin{array}{l}\text { Bloques y placas filtrantes de } \\
\text { pasta de papel }\end{array}$ & 0 & 0 & 3 & 1 & 0 \\
\hline 4813 & Papel de fumar & 0 & 0 & 74 & 0 & 0 \\
\hline 4814 & Papel para decorar & 0 & 1,7 & 193 & 0 & 0 \\
\hline 4815 & $\begin{array}{l}\text { Cubresuelos con soporte de papel } \\
\text { o cartón }\end{array}$ & 0 & 0 & 0 & 0 & 0 \\
\hline 4816 & $\begin{array}{l}\text { Los demás: papel carbón y papel } \\
\text { autocopia }\end{array}$ & 0 & 0,2 & 58 & 1 & 0 \\
\hline 4817 & $\begin{array}{l}\text { Sobres, sobres carta y tarjetas } \\
\text { postales }\end{array}$ & 0,1 & 25,6 & 77 & 0 & 0 \\
\hline 4818 & $\begin{array}{l}\text { Los demás papeles del tipo utilizado } \\
\text { para papel higiénico }\end{array}$ & 0,2 & 16,8 & 1.054 & 2 & 2 \\
\hline 4819 & $\begin{array}{l}\text { Cajas, sacos, bolsitas y demás } \\
\text { envases de papel o cartón }\end{array}$ & 0,4 & 310,6 & 1.182 & 2 & 45 \\
\hline 4820 & $\begin{array}{l}\text { Libros registro, libros de contabilidad, } \\
\text { talonarios, cuadernos }\end{array}$ & 0,1 & 349,4 & 705 & 0 & 1 \\
\hline 4821 & $\begin{array}{l}\text { Etiquetas de todas clases, de papel } \\
\text { o cartón }\end{array}$ & 0 & 14,8 & 222 & 1 & 13 \\
\hline 4822 & $\begin{array}{l}\text { Carretes o bobinas, de pasta de } \\
\text { papel, papel o cartón }\end{array}$ & 0 & 0 & 6 & 0 & 0 \\
\hline 4823 & Autoadhesivos & 0 & 76,1 & 702 & 1 & 7 \\
\hline Total & & 8 & 881 & 15.459 & 26 & 402 \\
\hline
\end{tabular}

Fuente: U.S. International Trade Commission, www.dataweb.usitc.gov 
fueron por US\$ 5,4 billones - de los cuales US\$2,8 billones fueron a Estados Unidos-.

Las exportaciones chilenas de madera y manufacturas de madera (HS 44) en 2002 alcanzaron a US\$ 1,1 billones, de los cuales 57\% fue a Estados Unidos. En el nivel más desagregado, las exportaciones más importantes son madera aserrada (HS 4407) por US\$ 392 millones, madera perfilada (HS 4409) por US\$ 192 millones, tableros de fibra de madera (HS 4411) por US\$ 131 millones, y aserrín (HS 4401) por US\$ 117 millones. Las exportaciones chilenas totales de madera en bruto (HS 4403) fueron sólo por US\$ 28 millones, mientras que las exportaciones de muebles fueron por US\$ 66 millones, la mayoría de las cuales fueron a Estados Unidos.

Lo anterior muestra que Chile es un importante exportador de madera, mientras que China es importador neto de madera. Sin embargo, las principales variedades exportadas por Chile son distintas de los tipos importados por China. Además, China es un exportador neto de productos que usan intensivamente madera y mano de obra, como manufacturas de madera y muebles. En otras palabras, los productores chilenos de madera enfrentan potencial competencia de China en productos derivados de la madera. Es importante enfatizar la palabra potencial porque Chile no es un importante exportador de artículos de madera y muebles, sino de madera y pulpa de madera. Sin embargo, la alta penetración de China en los mercados de productos de madera y muebles puede en parte explicar esta estructura de exportaciones.

Un patrón similar se observa en el caso del papel y cartón (HS 48). El Cuadro $\mathrm{N}^{\circ} 4.5$ muestra que China es un importador neto de papel, pero un exportador de manufacturas de papel y cartón, como bolsas, cajas y cuadernos, entre otros. Al mismo tiempo, Chile es un importante exportador de papel, pero no a Estados Unidos. El año 2002, las exportaciones totales chilenas de HS 48 fueron por US\$ 341 millones. Así, Chile enfrenta potencial competencia de China en productos derivados del papel.

\subsection{Comercio bilateral}

El Cuadro $\mathrm{N}^{\circ} 5$ detalla los flujos bilaterales de comercio en millones de dólares entre Chile y China el año 2002, clasificados en 2 dígitos HS, y el Cuadro $\mathrm{N}^{\circ} 6$ detalla los 15 principales productos exportados e importador por Chile en 2003, clasificados a 8 dígitos HS. Las importaciones chilenas desde China están concentradas en pocas industrias: cuero (HS 42), prendas de vestir (HS 61, 62), calzado (HS 64) y juguetes (HS 


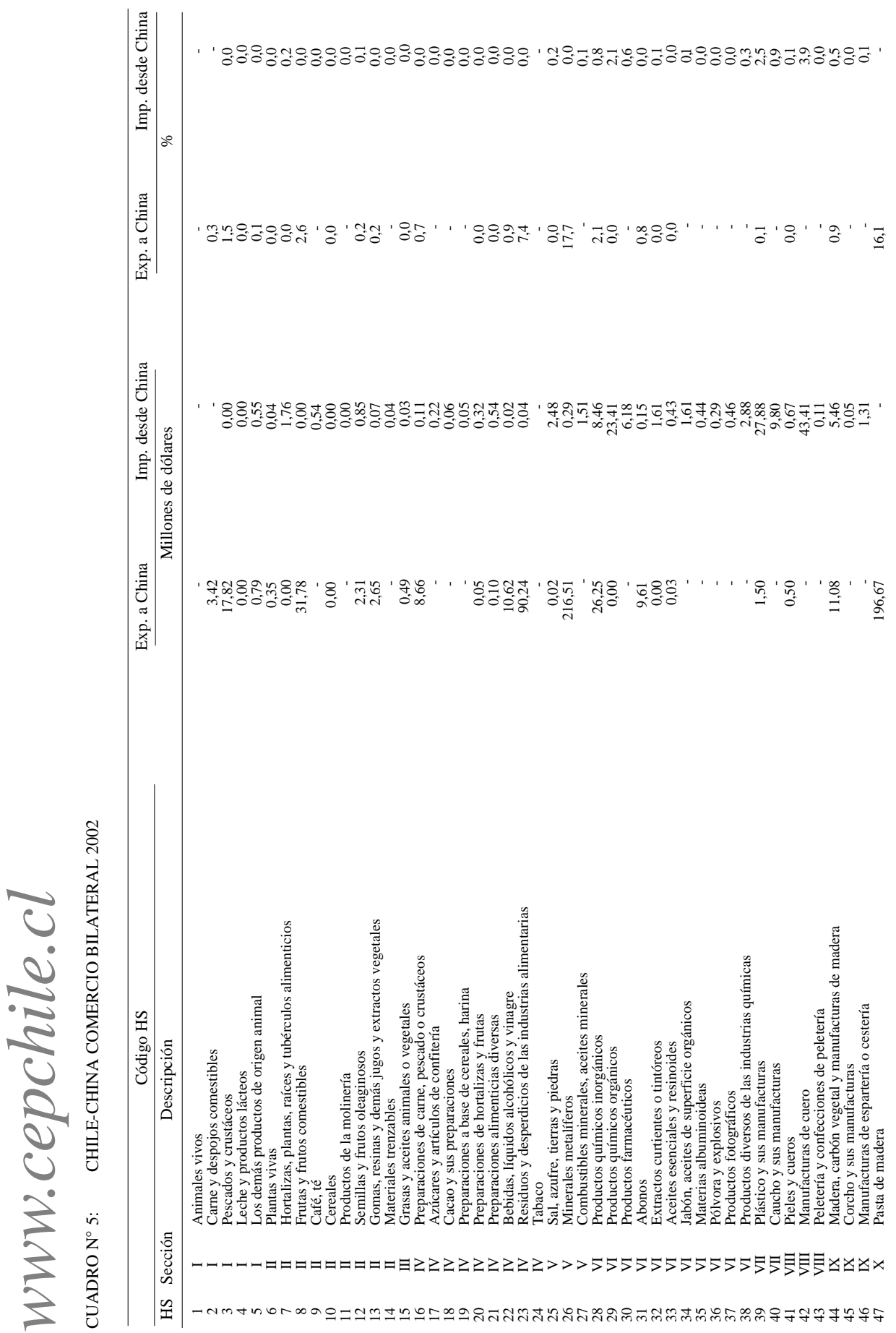


음

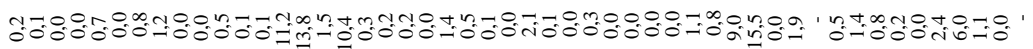

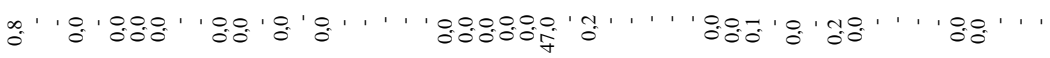

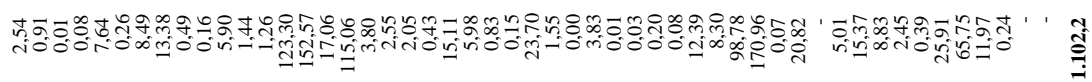

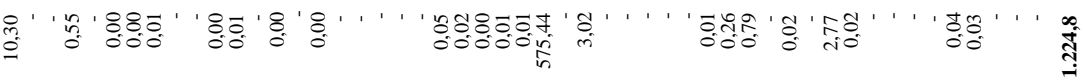

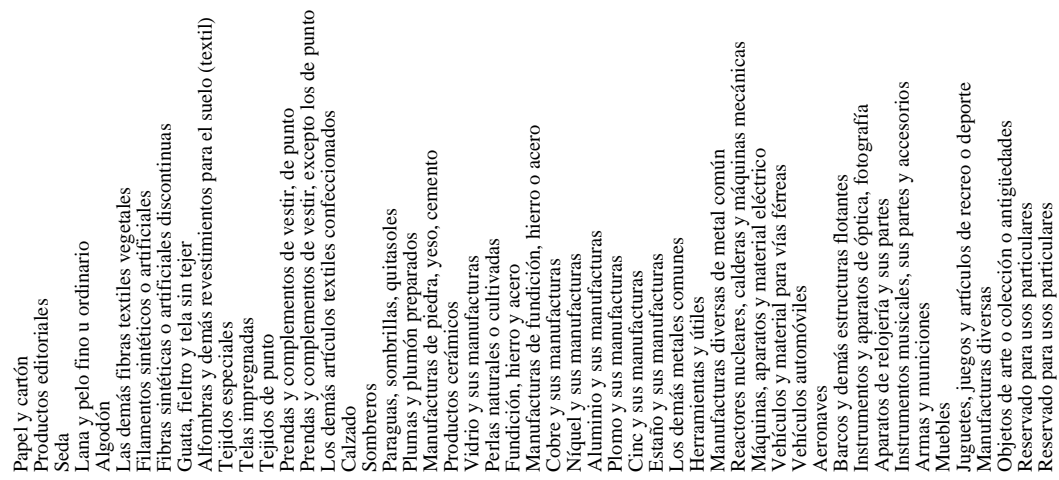

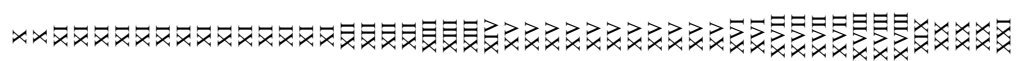

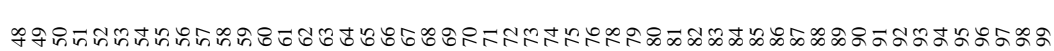


CUADRO N ${ }^{\circ}$ 6: $\quad$ PRINCIPALES PRODUCTOS DE INTERCAMBIO CHILE-CHINA 2003

(Millones de dólares)

A) Principales exportaciones a China

\begin{tabular}{rrlc}
\hline Código & Capítulo Descripción & Exportaciones \\
\hline 74031100 & 74 & Cátodos y secciones de cátodo & 958,9 \\
26030000 & 26 & Minerales de cobre y sus concentrados & 370,1 \\
47032100 & 47 & Pasta química conífera & 127,3 \\
23012013 & 23 & Harina de pescado & 53,2 \\
47031100 & 47 & Pasta química conífera & 53,0 \\
23012011 & 23 & Harina de pescado & 25,3 \\
8061030 & 8 & Uva fresca & 23,2 \\
26011210 & 26 & Pellets de minerales de hierro & 21,5 \\
23012012 & 23 & Harina de pescado & 20,5 \\
47032900 & 47 & Pasta química conífera & 19,5 \\
29051100 & 29 & Metanol & 18,5 \\
28342100 & 28 & Nitrato de potasio & 16,8 \\
74020010 & 74 & Cobre para el afino & 14,8 \\
44071019 & 44 & Las demás maderas aserradas de pino & 13,5 \\
16059090 & 16 & Los demás moluscos & 12,1 \\
& & & $1.748,2$ \\
Total muestra & & & $1.940,6$ \\
Total exportaciones & &
\end{tabular}

B) Principales importaciones desde China

\begin{tabular}{lclc}
\hline Código & Capítulo & Descripción & Importaciones \\
\hline 61091011 & 61 & T-shirts y camisetas punto algodón & 18,6 \\
85219000 & 85 & Los demás aparatos de grabación & 17,0 \\
62034291 & 62 & Pantalones largos de algodón & 16,8 \\
85273190 & 85 & Los demás aparatos receptores de radio & 16,3 \\
64039992 & 64 & Los demás calzados & 15,3 \\
95039010 & 95 & Los demás juguetes de plástico & 14,6 \\
61103010 & 61 & Suéteres de fibras sintéticas & 13,4 \\
84716031 & 84 & Monitores & 12,7 \\
62052010 & 62 & Camisas de algodón para hombres & 12,6 \\
85421000 & 85 & Tarjetas provistas de un circuito integrado & 11,7 \\
64039991 & 64 & Los demás calzados con plantilla & 11,3 \\
42031010 & 42 & Chaquetas, chaquetones y casacas de cuero & 10,8 \\
62046291 & 62 & Pantalones largos de algodón para mujer & 10,8 \\
64041990 & 64 & Los demás calzados con suela de caucho & 10,3 \\
64029991 & 64 & Los demás calzados para hombres & 10,2 \\
& & & 202,4 \\
Total muestra & & & $1.367,2$ \\
Total importaciones & &
\end{tabular}

Fuente: Banco Central de Chile: Indicadores de Comercio Exterior, varios números. 
95) representan el 45,3\% de las importaciones desde China. Un 24,5\% adicional está dado por reactores nucleares, máquinas mecánicas (HS 84) y maquinaria eléctrica (HS 85). La estructura de importaciones de Chile es similar a la de Estados Unidos, con una correlación de las participaciones de las importaciones de 0,78 y un índice de similitud de importaciones ${ }^{12}$ calculado a 2 dígitos HS de 68.

Las exportaciones chilenas están concentradas en muy pocos productos: cobre (HS 74), minerales metalíferos —especialmente de cobre(HS 26), pasta de madera (HS 47) y residuos y desperdicios de las industrias alimentarias (HS 23) representan el 85,4\% del total de exportaciones. En particular, los principales productos de exportaciones a China son cobre y concentrados de cobre (HS 7403 y 2603), pasta de madera (HS 4703) y harina de pescado (HS 2301). Aparte de cobre, ninguno de estos productos se exporta a Estados Unidos en volúmenes significativos, aun cuando EE.UU. es un importante importador de pulpa de madera desde Canadá. Los principales destinos de pulpa de madera de Chile son China, Corea del Sur, Taiwán y países europeos ${ }^{13}$. Otros productos exportados por Chile son productos químicos, uva y madera aserrada. Es evidente que las exportaciones chilenas a China no son un fiel reflejo de la estructura agregada de las exportaciones chilenas ${ }^{14}$.

Las exportaciones a China están dominadas por el cobre. El crecimiento en el consumo chino de cobre refinado ha sido muy grande en los últimos años, desde 1,4 millones de toneladas en 1998 hasta 2,7 millones de toneladas en 2002. Esto lo transforma en el mayor consumidor mundial de cobre, con una participación de $17,4 \%$ en $2002^{15}$. Dado que la capacidad de producción en mina en China es relativamente baja (0,6 millones de toneladas en 2002 , que representa un $4,1 \%$ del total mundial), el aumento en el consumo se ha traducido en un fuerte incremento en las importaciones, tanto de cátodos como de concentrado ${ }^{16}$. El crecimiento en el consumo se explica básicamente por la cantidad de proyectos de construcción y electrificación, además del aumento del consumo industrial — como la producción de automóviles-.

${ }^{12}$ Calculado igual que el ESI pero con participación en importaciones.

${ }^{13}$ Banco Central de Chile, Informe de Comercio Exterior.

${ }_{14}$ Datos del nivel de 3 dígitos ISIC muestran que el año 2002 el 34,8\% de las exportaciones chilenas fueron cobre, el $9,4 \%$ productos agrícolas, un $15,4 \%$ productos alimentarios, $6,3 \%$ madera y manufacturas de madera, $5,7 \%$ papel, y 3,8\% productos químicos.

${ }^{15}$ Véase Bureau of Metal Statistics (2003), y Comisión Chilena del Cobre (Cochilco), 2003.

${ }^{16}$ China tiene una alta capacidad de refinamiento de cobre $-1,58$ millones de toneladas anuales-, bastante más que su capacidad de producción en mina. Luego, las importaciones de concentrados de cobre para refinar en China son altas. 
El Cuadro $\mathrm{N}^{\circ} 7$ detalla la evolución de las exportaciones chilenas en los dos principales productos de cobre a partir de 1997. La participación de China de las exportaciones de cátodos aumentó de 3,1\% en 1998 a $22 \%$ en 2003. En el caso de concentrados de cobre, la participación de China aumentó de $9,1 \%$ a $15 \%$ en el mismo período.

CUADRO N $\mathrm{N}^{\circ}$ 7: PRINCIPALES DESTINOS DE EXPORTACIONES DE COBRE DE CHILE (Millones de dólares)

HS 2603.0000: Concentrados de cobre

\begin{tabular}{lrrrrrr}
\hline Destino & 1998 & 1999 & 2000 & 2001 & 2002 & 2003 \\
\hline Japón & 412,9 & 669,2 & 885,3 & 769,6 & 607,3 & 824,1 \\
China & 98,6 & 139,6 & 273,1 & 282,4 & 184,5 & 370,1 \\
Alemania & 70,0 & 133,4 & 138,5 & 186,2 & 107,9 & 214,4 \\
Estados Unidos & 70,0 & 19,1 & 0,0 & 18,9 & 82,1 & 11,0 \\
Brasil & 61,5 & 124,8 & 195,1 & 177,1 & 125,9 & 150,6 \\
Perú & 52,5 & 40,6 & 37,4 & 53,4 & 34,5 & 3,6 \\
Canadá & 49,2 & 61,8 & 128,8 & 131,5 & 60,3 & 50,6 \\
Corea del Sur & 40,7 & 122,2 & 189,5 & 130,9 & 127,2 & 248,9 \\
India & 26,1 & 86,1 & 115,0 & 108,0 & 160,3 & 195,7 \\
Total muestra & 881,5 & $1.396,8$ & $1.962,6$ & 1.858 & $1.489,9$ & $2.069,0$ \\
Total exportaciones & $1.083,0$ & $1.663,4$ & $2.393,7$ & $2.149,6$ & $1.734,3$ & $2.444,0$ \\
\hline
\end{tabular}

HS 7403.1100: Cátodos

\begin{tabular}{lrrrrrr}
\hline Destino & 1998 & 1999 & 2000 & 2001 & 2002 & 2003 \\
\cline { 2 - 7 } & & & & & & \\
Inglaterra & 657,0 & 560,4 & 526,8 & 724,6 & 262,8 & 105,1 \\
Italia & 450,6 & 427,3 & 536,2 & 583,1 & 593,6 & 613,8 \\
Taiwán & 365,8 & 304,5 & 367,7 & 218,8 & 344,0 & 392,1 \\
Francia & 281,3 & 346,2 & 408,3 & 417,1 & 436,1 & 491,9 \\
Japón & 237,9 & 200,0 & 261,1 & 142,1 & 108,0 & 126,9 \\
Estados Unidos & 206,0 & 413,3 & 407,6 & 563,5 & 538,4 & 262,7 \\
Corea del Sur & 192,6 & 346,0 & 393,9 & 242,2 & 383,1 & 436,5 \\
Brasil & 186,7 & 151,2 & 253,6 & 204,0 & 133,5 & 198,8 \\
Alemania & 150,3 & 174,8 & 79,3 & 103,5 & 88,6 & 111,7 \\
China & 108,7 & 98,9 & 376,0 & 321,4 & 565,1 & 958,9 \\
Holanda & 107,9 & 197,8 & 128,5 & 85,7 & 131,7 & 149,7 \\
México & 103,7 & 165,3 & 247,1 & 177,8 & 102,5 & 101,8 \\
Total muestra & $3.048,5$ & $3.385,8$ & $3.986,2$ & $3.783,7$ & $3.687,4$ & 3.950 \\
Total exportaciones & $3.452,6$ & $3.651,1$ & $4.406,5$ & $4.128,2$ & $4.085,6$ & $4.358,0$ \\
\hline
\end{tabular}

Fuente: ProChile. 


\section{Acciones comerciales}

\subsection{Disputas comerciales}

Los Cuadros $N^{\text {os. }} 8,9$ y 10 detallan todas las iniciaciones y medidas comerciales emprendidas por Chile entre 1981 y 2002, ordenadas por año, sector y países de origen ${ }^{17}$. Las investigaciones las pueden solicitar empresas privadas o instituciones gubernamentales (por oficio). Cada iniciación es estudiada por la Comisión Nacional de Distorsiones de Precios, que puede recomendar medidas, provisionales o definitivas. Las medidas se clasifican en tres categorías: salvaguardias, medidas compensatorias y medidas antidumping ${ }^{18}$.

Las iniciaciones totales en el período analizado fueron 215 , pero éstas pueden estar dirigidas a más de un país, por lo que el Cuadro $\mathrm{N}^{\circ} 10$ contiene 395 iniciaciones. Resulta interesante observar que las iniciaciones eran más comunes en la década de 1980 que en los 90. Una explicación dice relación con la crisis de 1982. Las iniciaciones en los 80 podrían ser parte de un brote proteccionista en la primera mitad de los 80 - que elevó la tarifa promedio de $6,3 \%$ en 1982 a $15,5 \%$ en $1985^{19}$ - más que obedecer a problemas específicos en algunos productos.

El sector con mayor número de iniciaciones es el textil, con 67. Le siguen metalmecánica (26), productos agrícolas (15), alimentos (13), maquinaria eléctrica y no eléctrica (16), lácteos (17), goma y plástico (17), químicos (17) y vidrio y cerámica (10). Los países más afectados fueron Brasil, Argentina, Perú, Corea del Sur y China. China ha sido objeto de un $5,6 \%$ (22) del total de iniciaciones y $6 \%$ del total de medidas (15). Este número es relativamente bajo comparado con el patrón mundial de medidas contra China ${ }^{20}$. Una posible explicación es que la penetración de productos chinos — especialmente en la década de 1990 — no ha desplazado la producción local sino las importaciones de terceros países. El Cuadro $\mathrm{N}^{\circ} 11$ detalla todas las iniciaciones chilenas en contra de China ${ }^{21}$. Casi

\footnotetext{
${ }^{17}$ Banco Central de Chile: Antecedentes Estadísticos 1981-2002.

18 Ver "Antecedentes Estadísticos 1981-2002" de la Comisión Nacional Encargada de Investigar la Existencia de Distorsiones en el Precio de las Mercaderías Importadas, Banco Central de Chile, para un detalle de los procedimientos en cada investigación. Las medidas antidumping fueron legalizadas en Chile en 1993 (Ley $\mathrm{N}^{\circ}$ 18.525).

${ }^{19}$ Calculado como la razón entre ingresos por concepto de derechos de importación y las importaciones totales. Ver Jofré, Lüders y Wagner (1998).

${ }^{20}$ De acuerdo con la OMC, entre 1995 y junio 2003, China fue objeto de 324 iniciaciones antidumping, de las cuales 232 terminaron con medidas en contra de productos chinos.

${ }^{21}$ Se incluyen las iniciaciones dirigidas explícitamente contra China.
} 


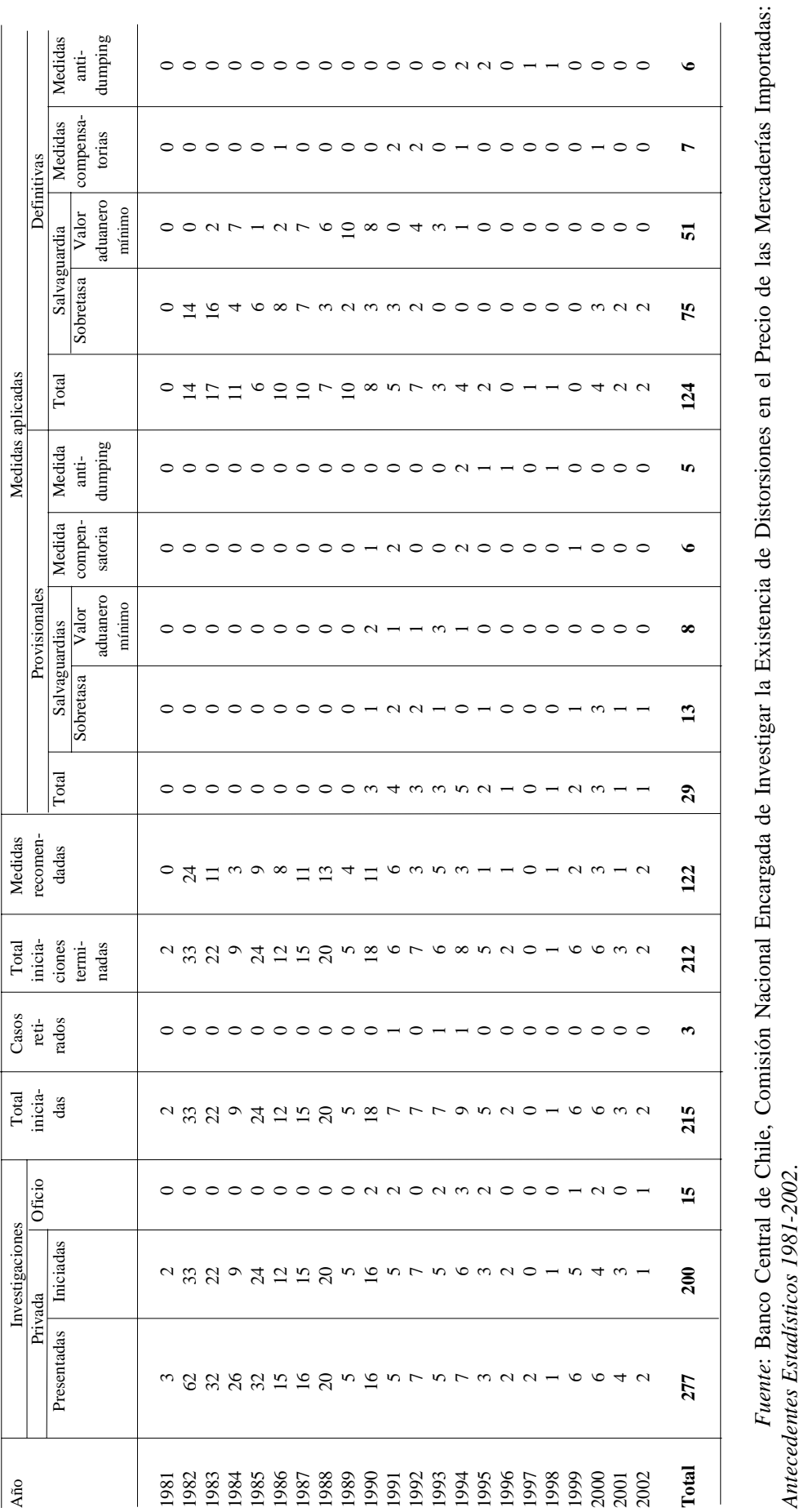




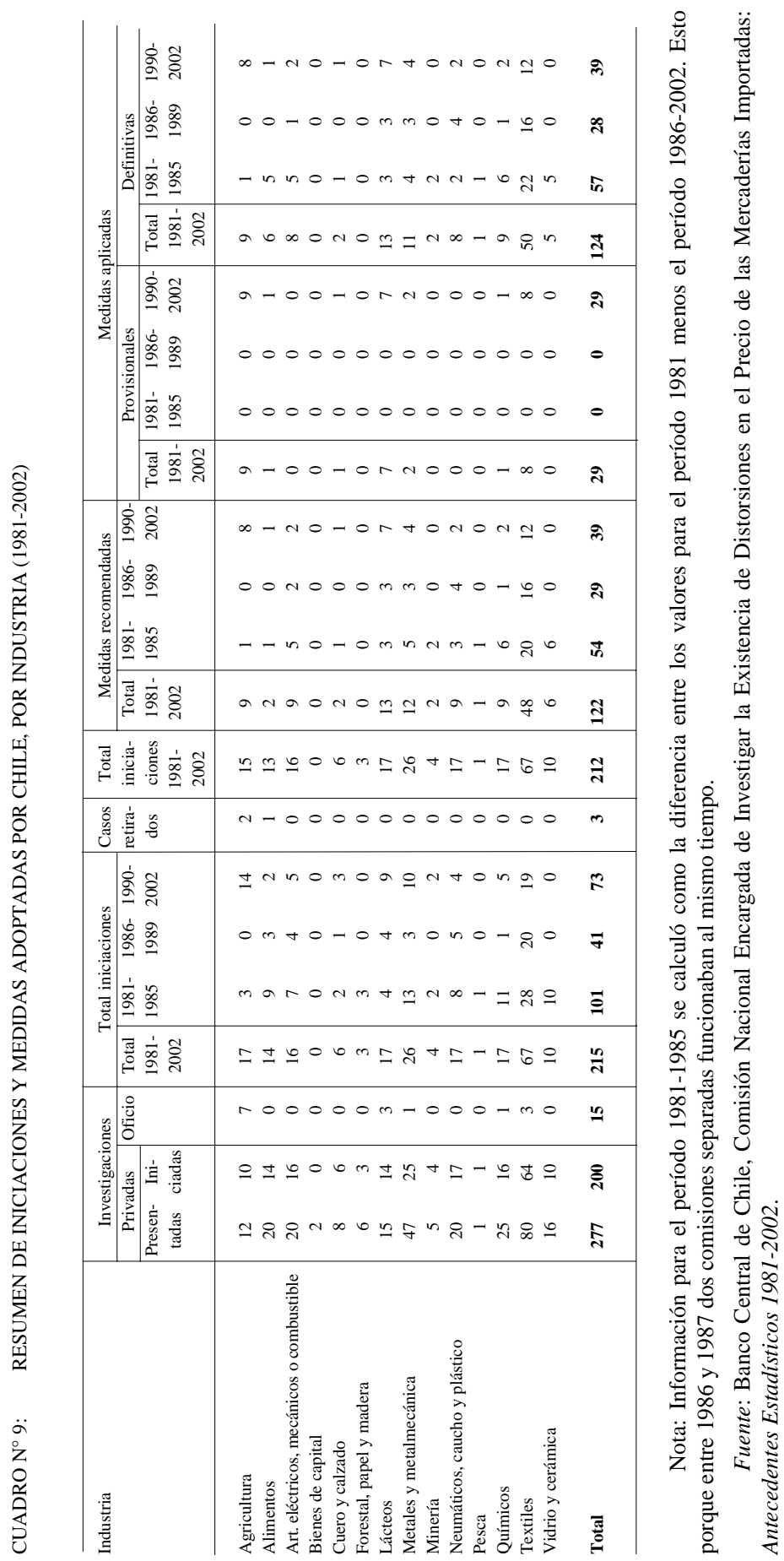




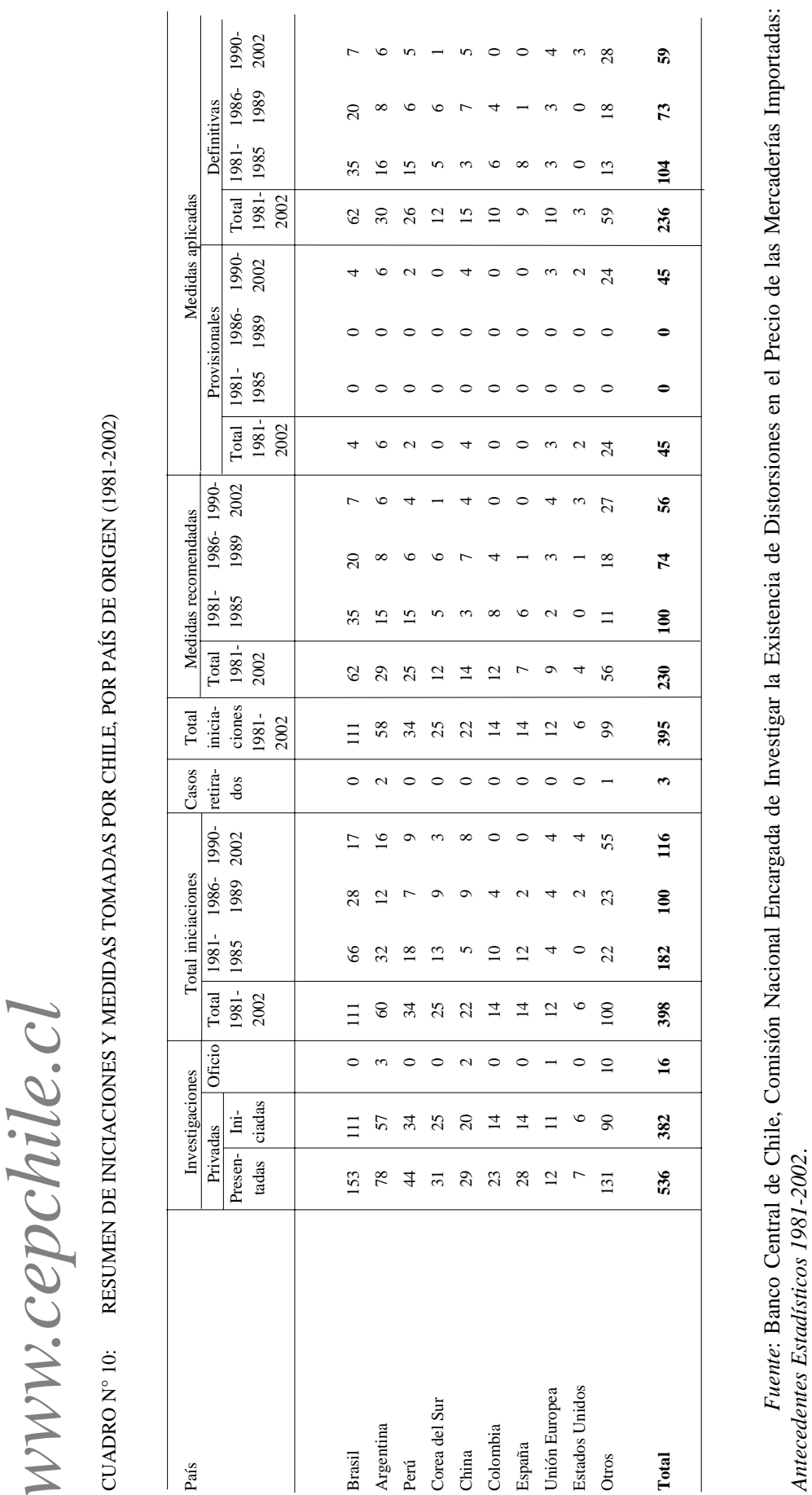


todas son en prendas de vestir, textiles y calzado — patrón similar se observa en las iniciaciones contra China a nivel mundial- y ninguna en maquinaria mecánica y eléctrica (HS 84 y 85), donde la penetración de productos ha sido también importante.

\subsection{Posición chilena en acceso de China a la OMC}

Un aspecto central en la postulación y eventual ingreso de un país a la OMC (Organización Mundial del Comercio) es la oferta que el país postulante entrega a los países miembros de la OMC respecto de apertura de mercados. Esta oferta es estudiada por los países, quienes pueden negociar bilateralmente con el país postulante aspectos específicos - especialmente en lo referido a la apertura de mercados-. Las contrapropuestas pueden ser aceptadas o rechazadas por el país postulante, que finalmente hace la oferta definitiva, que es votada por los miembros de la $\mathrm{OMC}^{22}$.

La posición adoptada por Chile en el proceso de postulación china está detallada en el Cuadro $\mathrm{N}^{\circ} 12$, que muestra los productos en los cuales Chile solicitó mejoras en la oferta de China, agrupados en secciones ${ }^{23}$. Para cada sección se detalla en la columna 3 el número de productos en que se solicitaron mejoras en la oferta china. Las columnas 4 a 6 muestran para cada sección el número de peticiones aceptadas por China, el número de peticiones rechazadas y el número de productos en los cuales la oferta final de China fue mejor que la petición Chilena. Así, en los productos de la sección I (animales vivos y productos del reino animal), Chile solicitó mejoras en 7 productos, de las cuales China aceptó 5 y rechazó 2. Sin embargo, la tarifa final ofrecida por China luego de negociar con el resto de los países miembros de la OMC fue menor que la pedida por Chile en todos los productos.

Aun cuando China rechazó la mayor parte de las peticiones chilenas, las tarifas finales fueron casi siempre menores que las pedidas por Chile, lo que muestra que otros países con mayor fuerza negociadora también solicitaron menores tarifas en esos productos. La mayoría de las peticiones fueron en productos agrícolas y madereros. El total de productos incluidos en la lista representa sólo el 5,7\% de las exportaciones a China el año 2002. Esto se explica porque la mayoría de los productos que Chile

22 Ver "Technical Note on the Accession Process: Note by the Secretariat", Doc. 032861, OMC, 2003, para un detalle del procedimiento de ingreso a la OMC.

${ }^{23}$ Las peticiones específicas se refieren a productos clasificados a 8 dígitos HS. El Cuadro $\mathrm{N}^{\circ} 5$ muestra las 99 categorías agrupadas en 21 secciones. 


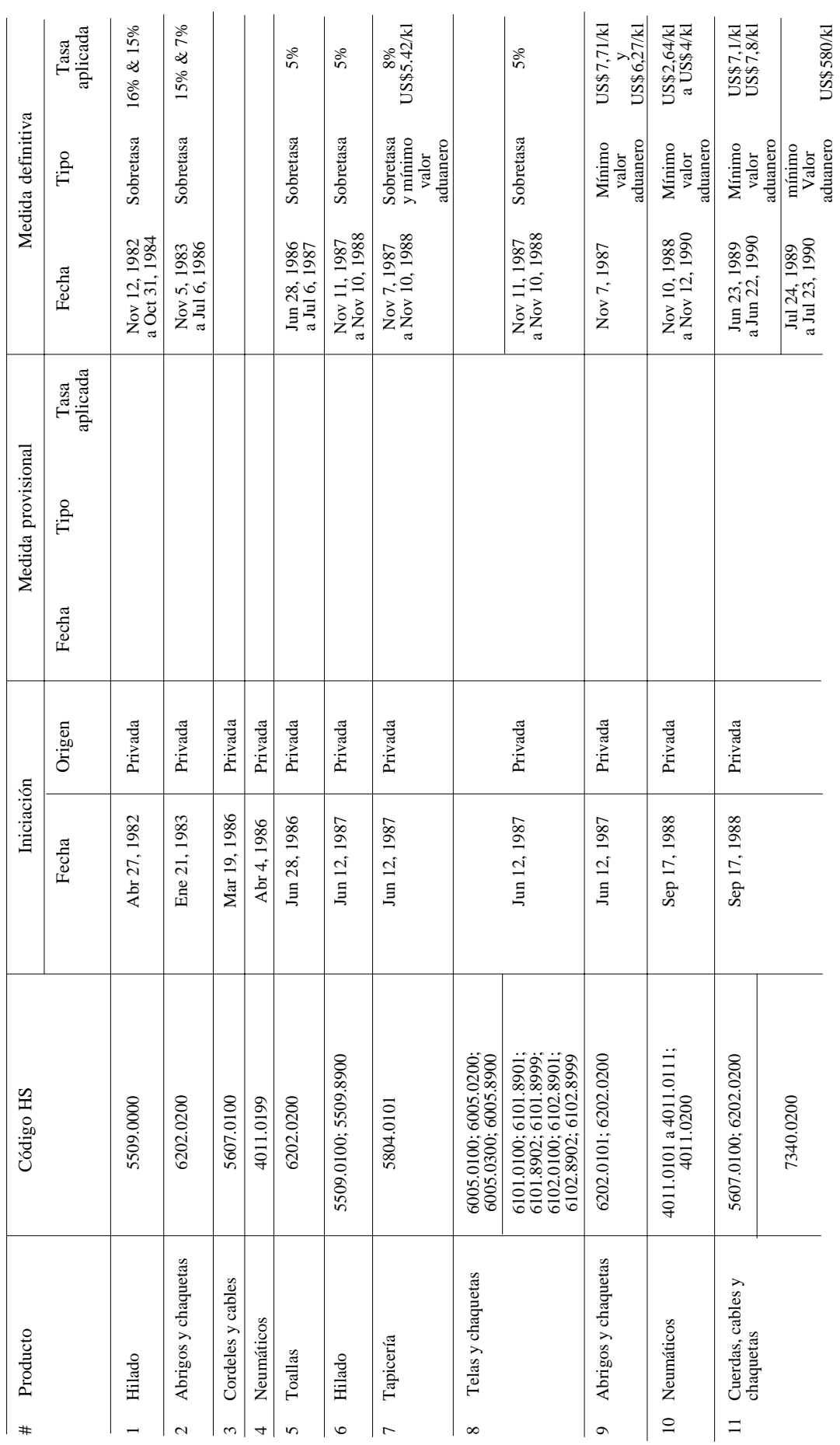




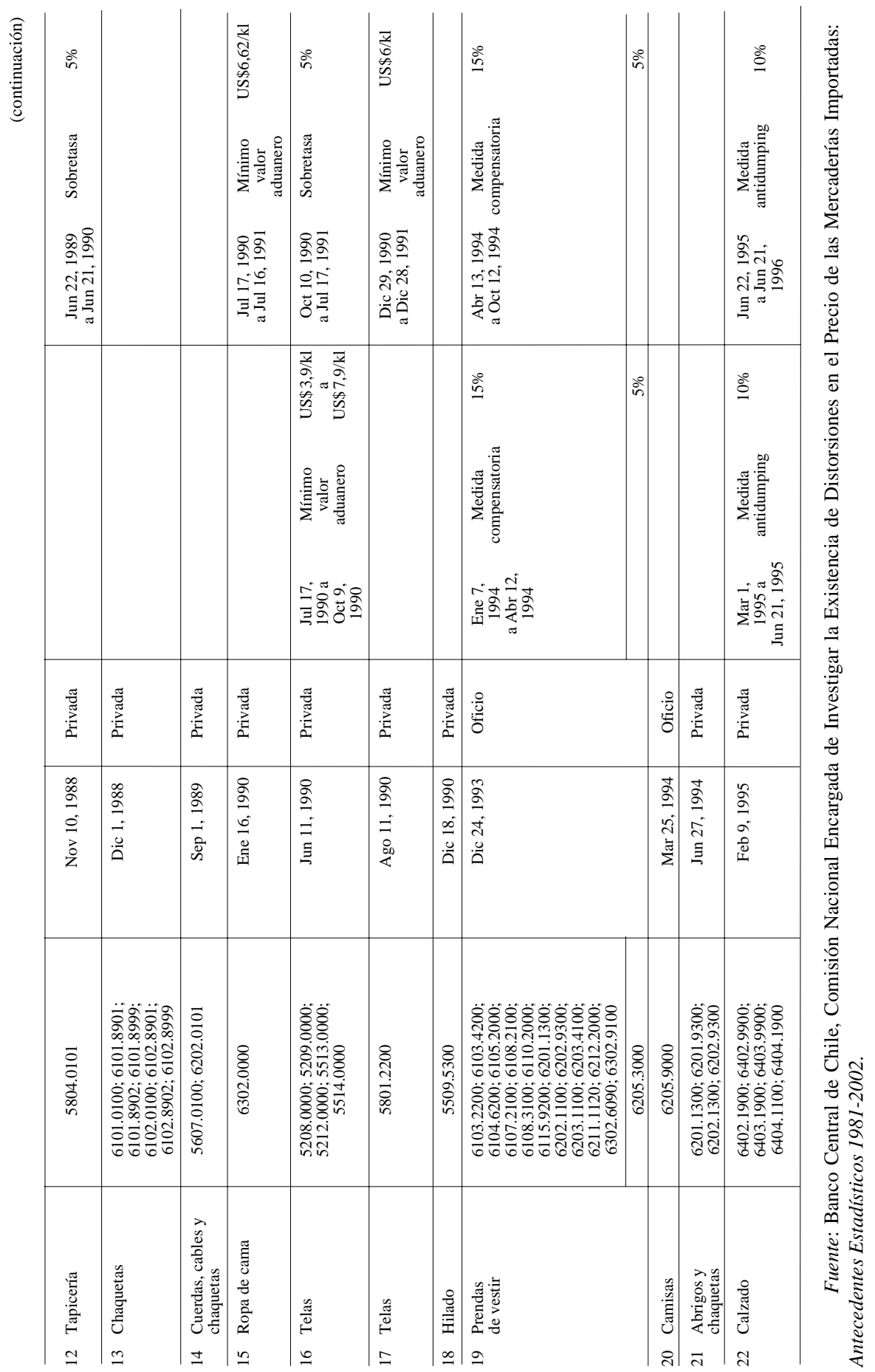


CUADRO $\mathrm{N}^{\circ}$ 12: $\quad$ LISTA PRIORITARIA DE CHILE

\begin{tabular}{|c|c|c|c|c|c|c|}
\hline \multirow[t]{2}{*}{ Sección } & \multirow[t]{2}{*}{ Descripción } & \multirow[t]{2}{*}{$\#$} & \multicolumn{2}{|c|}{ Respuesta de China } & \multirow{2}{*}{$\begin{array}{c}\text { \# Tarifa final > } \\
\text { petición } \\
\text { chilena }\end{array}$} & \multirow{2}{*}{$\begin{array}{c}\text { Exportaciones } \\
\text { a China } \\
2003 \\
\text { Millones de US }\end{array}$} \\
\hline & & & $\begin{array}{c}\mathrm{Y} \\
\text { (Aceptada) }\end{array}$ & $\begin{array}{c}\mathrm{N} \\
\text { (Rechazada) }\end{array}$ & & \\
\hline I & $\begin{array}{l}\text { Animales vivos y productos } \\
\text { del reino animal }\end{array}$ & 7 & 5 & 2 & 0 & 10,9 \\
\hline II & Productos del reino vegetal & 9 & 0 & 9 & 1 & 30,6 \\
\hline III & $\begin{array}{l}\text { Grasas y aceites animales o } \\
\text { vegetales }\end{array}$ & 2 & 1 & 1 & 0 & 0,3 \\
\hline IV & $\begin{array}{l}\text { Productos de las industrias } \\
\text { alimentarias }\end{array}$ & 9 & 1 & 8 & 2 & 18,6 \\
\hline VI & $\begin{array}{l}\text { Productos de las industrias } \\
\text { químicas }\end{array}$ & 2 & 0 & 2 & 0 & 5,9 \\
\hline IX & $\begin{array}{l}\text { Madera y manufacturas de } \\
\text { madera }\end{array}$ & 9 & 3 & 6 & 0 & 0,1 \\
\hline $\mathrm{X}$ & Pasta de madera & 1 & 1 & 0 & 0 & 7,3 \\
\hline XI & $\begin{array}{l}\text { Textiles y sus } \\
\text { manufacturas }\end{array}$ & 3 & 0 & 3 & 0 & 0,4 \\
\hline XV & $\begin{array}{l}\text { Metales comunes y } \\
\text { manufacturas }\end{array}$ & 1 & 0 & 1 & 0 & 0,0 \\
\hline
\end{tabular}

Fuente: Dirección Económica de la Cancillería, Ministerio de Relaciones Exteriores, Chile.

exporta a China están sujetos a bajas tarifas, como muestra el Cuadro $\mathrm{N}^{\circ} 13$. Los primeros 7 productos representan $83 \%$ de las exportaciones a China y están sujetos a tarifas muy bajas.

Lo anterior no significa que la estructura de tarifas en China no afecte a las exportaciones chilenas, ya que las tarifas en otros productos que Chile exporta a otros países — como productos agrícolas- son bastante altas. Esto puede explicar en parte la baja penetración de estos productos en China. Sin embargo, es razonable pensar que las mayores dificultades que enfrentan los exportadores chilenos están relacionadas con barreras no arancelarias, administrativas y de distribución interna. Este último punto es muy importante, ya que el acceso a los mercados domésticos chinos se hace en gran parte a través de canales de distribución dominados por el Estado, cuya tortuosa y a veces poco transparente estructura sirve como medio para proteger a las empresas domésticas. (Ver discusión más abajo.) 
CUADRO N ${ }^{\circ}$ 13: $\quad$ PRINCIPALES EXPORTACIONES CHILENAS A CHINA Y TARIFAS EN CHINA

\begin{tabular}{|c|c|c|c|c|c|c|c|}
\hline \multirow[t]{2}{*}{$\#$} & \multirow[t]{2}{*}{ Código } & \multirow[t]{2}{*}{ Descripción } & \multicolumn{2}{|c|}{$\begin{array}{l}\text { Exportaciones } \\
\text { chilenas } \\
2002\end{array}$} & \multirow{2}{*}{$\begin{array}{c}\text { Tarifa en } \\
\text { China } \\
2002 \\
\%\end{array}$} & \multirow{2}{*}{$\begin{array}{c}\text { Tarifa } \\
\text { final } \\
\%\end{array}$} & \multirow{2}{*}{$\begin{array}{c}\text { Fecha de } \\
\text { implemen- } \\
\text { tación } \\
\text { (año) }\end{array}$} \\
\hline & & & MM US\$ & $\%$ & & & \\
\hline 1 & 74031100 & $\begin{array}{l}\text { Cátodos y secciones } \\
\text { de cátodo }\end{array}$ & 565,1 & 45,4 & 2 & & \\
\hline 2 & 26030000 & Minerales de cobre y & & & & & \\
\hline & & sus concentrados & 184,5 & 14,8 & 0 & & \\
\hline 3 & 47032100 & Pasta química conífera & 118,8 & 9,5 & 0 & & \\
\hline 4 & 23012012 & Harina de pescado & 52,4 & 4,2 & 2 & & \\
\hline 5 & 47031100 & Pasta química conífera & 51,8 & 4,2 & 0 & & \\
\hline 6 & 23012013 & Harina de pescado & 32,3 & 2,6 & 2 & & \\
\hline 7 & 47032900 & Pasta química conífera & 26,1 & 2,1 & 0 & & \\
\hline 8 & 8061030 & Uva fresca & 19,7 & 1,6 & 29,2 & 13 & 2004 \\
\hline 9 & 26011111 & Minerales finos de hierro & & & & & \\
\hline & & y sus concentrados & 13,9 & 1,1 & 0 & & \\
\hline 10 & O 26011210 & $\begin{array}{l}\text { Pellets de minerales de } \\
\text { hierro }\end{array}$ & 13,8 & 1,1 & 0 & & \\
\hline 11 & 128342100 & Nitrato de potasio & 10,5 & 0,8 & 5,5 & & \\
\hline 12 & 244071019 & $\begin{array}{l}\text { Las demás maderas } \\
\text { aserradas de pino }\end{array}$ & 10,3 & 0,8 & 1 & & \\
\hline 13 & 316059090 & Los demás moluscos & 8,0 & 0,6 & 18.3 & 5 & 2005 \\
\hline 14 & 422042991 & Los demás vinos tintos & 7,4 & 0,6 & 47 & 20 & 2004 \\
\hline 15 & 548010010 & Papel prensa en bobinas & 7,3 & 0,6 & 12 & 5 & 2006 \\
\hline 16 & 631043000 & Sulfato de potasio & 7,3 & 0,6 & 4 & & \\
\hline 17 & 728012000 & Yodo & 5,9 & 0,5 & 5,5 & & \\
\hline 18 & 828369100 & Carbonato de litio & 5,6 & 0,5 & 7 & 5,5 & 2002 \\
\hline 19 & 98094010 & Ciruelas frescas & 5,6 & 0,4 & 28 & 10 & 2004 \\
\hline 20 & O 23012011 & Harina de pescado & 4,8 & 0,4 & 2 & & \\
\hline 21 & 126080000 & $\begin{array}{l}\text { Minerales de cinc y sus } \\
\text { concentrados }\end{array}$ & 4,0 & 0,3 & 0 & & \\
\hline 22 & 228100020 & Ácidos bóricos & 3,9 & 0,3 & 7 & 5,5 & 2002 \\
\hline 23 & 374040011 & Ánodos gastados & 3,5 & 0,3 & 1,5 & & \\
\hline 24 & 43037912 & Mero & 3,2 & 0,3 & 16 & 10 & 2004 \\
\hline 25 & 576020000 & $\begin{array}{l}\text { Desperdicios y desechos } \\
\text { de aluminio }\end{array}$ & 3,0 & 0,2 & 3 & 1,5 & 2002 \\
\hline 26 & 648109210 & Cartulinas & 3,0 & 0,2 & 11 & 5 & 2004 \\
\hline 27 & 774020010 & Cobre para el afino & 2,8 & 0,2 & 2 & & \\
\hline & Total mue & estral & $1.174,5$ & $\mathbf{9 4 , 4}$ & & & \\
\hline
\end{tabular}

Fuentes: Banco Central de Chile: Indicadores de Comercio Exterior, y European Community (2001). 


\section{Algunos elementos a considerar}

4.1. Chile, China y el cobre

El número del 10 de enero de 2004 de la revista China Review ${ }^{24}$ incluyó un artículo titulado "El Impacto de China en Chile", cuya pregunta principal era si Chile es uno de los países más beneficiados con el crecimiento en China. Esto debido al creciente rol de China en el mercado mundial de cobre y a la importancia del cobre en la economía chilena.

El año 2002 China se transformó en el mayor consumidor de cobre en el mundo y el mayor comprador de cobre chileno. El aumento en la demanda mundial - liderada por China - y restricciones de oferta han presionado al alza el precio del metal, cuyo promedio el año 2004 cercano a 125 centavos de dólar la libra es sólo inferior al nivel de 1995, el más alto en los últimos 25 años. Esto es beneficioso para Chile, tanto por sus efectos en el producto como por los mayores ingresos fiscales que ello implica ${ }^{25}$.

Los evidentes beneficios de un alto precio del cobre deben ser analizados con cuidado. Por una parte, el precio del metal está claramente por sobre su nivel de largo plazo, estimado de acuerdo con los costos de producción, refinamiento y distribución. De hecho, el presupuesto de la nación considera un precio promedio de mediano plazo cercano a los 80 centavos de dólar la libra. Luego, es importante que la política fiscal efectivamente considere el alto precio del cobre como un fenómeno transitorio, para evitar así gastar la mayor recaudación, con los posibles efectos macroeconómicos que un fuerte ciclo en el gasto fiscal podría causar. La implementación del fondo de estabilización del cobre, así como la regla de superávit estructural, apuntan en la dirección correcta ${ }^{26}$. Sin embargo, esta última está sujeta a problemas de inconsistencia intertemporal, dado que existen incentivos para manipular el ingreso potencial de la economía y así aumentar el nivel de gasto fiscal. En resumen, el fuerte aumento transitorio en el precio del cobre introduce en el corto plazo el riesgo de debilitar la estabilidad de la política fiscal —especialmente en períodos preelectorales- en un país caracterizado por instituciones fiscales relativamente sólidas.

${ }^{24}$ Ver www.livinginchina.com/review/archives/000625.html

${ }^{25}$ Meller (2000) presenta una reseña histórica de la importancia del cobre en la economía chilena. Larraín, Sachs y Warner (2000) discuten la relación entre precio del cobre, tipo de cambio real e inversión extranjera.

${ }^{26}$ Ver Morandé y Quiroz (1996) y Engel y Meller, eds. (1993). 
En el largo o mediano plazo, el alto precio del cobre dará origen a un aumento en la producción mundial —especialmente a través de nuevos proyectos - que permita suplir el crecimiento de la demanda concordante con el precio de largo plazo. Este ajuste podría perfectamente darse a través de un importante aumento en la producción doméstica y extranjera en Chile, como lo fue en la década de los 90. En otras palabras, en la medida en que la economía china siga creciendo a tasas cercanas a los 2 dígitos y que su demanda por cobre se expanda a tasas similares, es razonable esperar un aumento en la inversión extranjera en Chile así como en la producción nacional. Este efecto positivo será mayor en la medida en que las reglas del juego para la inversión en el sector sean más claras, predecibles y transparentes. Si se establecen barreras importantes a la inversión en el sector, el aumento en la producción mundial puede venir de otros países, perdiendo así Chile una importante oportunidad.

Un riesgo asociado a importantes flujos de inversión extranjera en el cobre es la posible apreciación del tipo de cambio real que los flujos de capital podrían generar, lo que afectaría a otros sectores exportadores. Este problema en la literatura ha sido denominado "enfermedad holandesa" (Corden, 1984). Un fuerte aumento en el precio de un producto intensivo en recursos naturales o el descubrimiento de grandes yacimientos generan un movimiento de recursos hacia ese sector y una apreciación del tipo de cambio real, con lo que la producción de otros sectores manufactureros se contrae.

Mientras las señales de precios sean las correctas, esto no es problemático, ya que los recursos se asignan hacia industrias más rentables, como sería el cobre en el caso chileno. Así, la contracción de otros sectores no es problemática porque la apreciación real sólo refleja una asignación de factores en los rubros en los cuales el país tiene mayor ventaja comparativa. Sin embargo, en la medida en que las otras industrias transables - como industrias manufactureras - estén sujetas a retornos crecientes a escala en su producción y que el desarrollo tecnológico sea mayor en estas industrias, el nivel de ingreso y la tasa de crecimiento en Chile se podrían ver afectados negativamente ${ }^{27}$.

Los posible efectos negativos para una economía de su excesiva dependencia en recursos naturales son un tema ampliamente debatido en la

${ }^{27}$ Matsuyama (1992) presenta un modelo con estas características. Otro mecanismo a través del cual una fuerte dotación de recursos naturales podría ser perjudicial para un país dice relación con la volatilidad de los precios relativos de los productos intensivos en recursos naturales. Precios relativos de los productos más volátiles hacen más costosas las decisiones de inversión, afectando la tasa de crecimiento. Meller (2000) critica éste y otros mecanismos a través de los cuales los recursos naturales podrían ser perjudiciales para un país. 
literatura. La evidencia sobre el rol de los recursos naturales en el nivel de desarrollo y crecimiento de países es diversa. Mientras algunos trabajos entregan evidencia empírica de una correlación negativa entre exportaciones de recursos naturales y crecimiento ${ }^{28}$, otros trabajos critican los resulta$\operatorname{dos}^{29}$. Los efectos negativos que los recursos naturales pudieran tener en el crecimiento son el argumento usado por Larraín, Sachs y Warner (2000), quienes argumentan que Chile -o cualquier otro país abundante en recursos naturales- podrá alcanzar un nivel de ingreso per cápita similar al de países desarrollados en la medida en que diversifique su estructura productiva y de exportaciones hacia productos más intensivos en capital o hacia servicios. Éste sería uno de los riesgos de un crecimiento ilimitado de la demanda por cobre en China, ya que impediría a Chile diversificar su estructura productiva y sus exportaciones.

Meller (2000) sin embargo presenta evidencia de que la asociación entre crecimiento y exportaciones de recursos naturales sería positiva y no negativa. De hecho, el período de mayor crecimiento en la producción y exportaciones de cobre - a partir de finales de los 80 — coincide con el período de mayor crecimiento en Chile. Cierto es que la participación del cobre en las exportaciones cayó fuertemente, pero eso se debió al fuerte aumento en las exportaciones de otros productos - también intensivos en recursos naturales.

Aun cuando los argumentos de que la dependencia de recursos naturales sea una traba para el desarrollo de largo plazo de Chile sean válidos —lo que es bastante discutible—, la recomendación de política económica no viene dada por elegir sectores ganadores. Larraín et al. (2000) recomiendan proveer un marco institucional que facilite la producción, inversión y exportaciones de productos manufacturados. Para ello argumentan a favor de un esquema cambiario flexible y de que Chile desarrolle una plataforma exportadora basada en redes de contacto internacionales que faciliten el intercambio de tecnología y conocimientos. Ellos también proponen un rol más activo del gobierno en promover la inversión extranjera en manufactura y servicios, fuertes inversiones en infraestructura -física y telecomunicaciones- y un fuerte impulso al mejoramiento de los estándares de calidad en educación. Finalmente, recomiendan una implementación adecuada de estrategias para el manejo intertemporal de los recursos que provienen de los sectores intensivos en recursos naturales.

${ }^{28}$ Ver Sachs y Warner (1997), Larraín, Sachs y Warner (2000) y las referencias de esos trabajos.

${ }^{29}$ Lederman y Maloney (2002) y Manzano y Rigobón (2001). 
Respecto de este último punto, vale la pena destacar que este tipo de estrategias — como el fondo del cobre y la regla de superávit estructuralpermite independizar la evolución del gasto fiscal del ciclo de ingresos fiscales; sin embargo, en principio no evitan fluctuaciones en el tipo de cambio. Para esto el fondo debe ahorrar en activos denominados en moneda extranjera, evitando así la apreciación del tipo de cambio en tiempos de bonanza de dólares y evitando su depreciación en períodos de precios bajos. Con esta estrategia, sin embargo, el valor del fondo queda sujeto a fluctuaciones del tipo de cambio. Más aún, no evita la apreciación de largo plazo en el tipo de cambio real, que sólo podrá ser afectada en la medida en que las políticas económicas cambien los determinantes de largo plazo del tipo de cambio real.

\subsection{Acuerdo de libre comercio Chile-China}

A mediados del año 2003 los gobiernos de Chile y China hicieron públicas sus intenciones de negociar un tratado de libre comercio (TLC). Aun cuando los detalles de las negociaciones no son públicos, algunos elementos clave de las negociaciones se pueden anticipar.

Un primer tema fundamental en la negociación de un acuerdo de este tipo dice relación con las barreras arancelarias en ambos países. En el caso de Chile, la eliminación de la tarifa pareja de $6 \%$ a los productos chinos no debiera representar un problema significativo para los productores chilenos en industrias sensibles a la penetración china, principalmente porque el nivel inicial de tarifas es bastante bajo. Además, resulta evidente que en textiles, ropa, calzado y productos electrónicos las ventajas de costos de China hacen muy difícil la viabilidad de los productores domésticos, a no ser que logren diferenciar sus productos. Desde el punto de vista de los consumidores, las ganancias de acceder a estos productos más baratos son inmensas.

Las barreras arancelarias que enfrentan los productos chilenos en China varían bastante. De hecho, las principales exportaciones chilenas a China están sujetas a muy bajos aranceles. Sin embargo, las tarifas para otros productos que Chile exporta a terceros países son bastante altas. Esto es evidente en la Tabla $\mathrm{N}^{\circ}$ 13. Por ejemplo, en el caso de los productos agrícolas, las manzanas están sujetas a una tarifa de 10\%, las uvas a 13\%, las paltas a $25 \%$, los kiwis a $20 \%$. Aun cuando estas tarifas pueden ser suficientes para limitar la penetración de productos chilenos, en mi opinión ellas explican sólo parcialmente la baja penetración de productos agrícolas $\mathrm{y}$ otros productos donde Chile tiene claras ventajas comparativas en el mercado doméstico chino. 
Restricciones no arancelarias de acceso al mercado chino parecen muy importantes, como medidas fitosanitarias o problemas de clasificación de bienes - especialmente en productos químicos-. Estas restricciones han limitado el acceso de productos chilenos y de otros países al mercado chino. Más aún, el acceso de productos extranjeros al mercado chino se hace a través de empresas distribuidoras, ya sean nacionales, regionales o por industria, que muchas veces representan una barrera administrativa muy efectiva para proteger el mercado local. De hecho, éste fue uno de los temas más discutidos en la postulación de China a la OMC, y los compromisos adquiridos por China son bastante amplios en lo que a acceso al mercado se refieren (Lardy, 2002).

Es aquí —más que en la disminución de barreras arancelarias- de donde se puede sacar mayor provecho a un tratado de libre comercio con China. Aun cuando los compromisos de China con la OMC podrían hacer pensar que la apertura de la distribución se va a llevar a cabo de todas maneras, la magnitud y rapidez de la apertura es incierta. Luego, es posible que un acuerdo bilateral facilite la entrada de productos chilenos.

Otro tema central en un acuerdo con China son los mecanismos de solución de controversias. Éste es un tema relevante en cualquier acuerdo, pero puede serlo más en el caso de China porque gran parte de las restricciones al acceso a los mercados chinos son de tipo administrativo, lo que puede llevar a mayores fricciones comerciales.

Desde la perspectiva China, un TLC con Chile constituye una especie de entrenamiento en lo que a negociación de TLC se refiere. En este sentido, China adquiere experiencia para futuros acuerdos comerciales con países de más peso económico en el contexto mundial. Otra ventaja para China puede ser aprovechar el acceso de Chile a terceros mercados. Para ello, Chile puede servir como plataforma de inversión y exportación a terceros mercados. Sin embargo, pienso que Chile no debiera esperar inversiones en industrias donde China tiene claras ventajas comparativas y Chile no las tiene, como ropa, calzados o productos electrónicos, sino más bien la inversión extranjera china podría esperarse más en industrias en las cuáles China quiere asegurar cierto grado de suministro - como el cobre, productos químicos o la madera-. En este caso, las exportaciones desde Chile no necesariamente serían hacia terceros países sino hacia China.

Así, las autoridades chinas pueden estar interesadas en acuerdos específicos de inversión extranjera ${ }^{30}$, o más bien en beneficios especiales a la inversión. Este último punto debe ser tratado con especial cuidado, y

${ }^{30}$ Chile firmó en marzo de 1994 un Acuerdo de Protección Mutua de Inversiones con China que establece reglas generales para la inversión extranjera en ambos países. 
subyace en un acuerdo comercial con China. La política chilena de atracción de inversión extranjera debe ser estable, clara y predecible, y no debe favorecer a productores extranjeros —en particular de fuentes específicas- en desmedro de los inversionistas nacionales.

\section{Conclusiones}

La apertura económica en China y su espectacular desempeño representan una importante fuente de oportunidades para Chile. El acceso más barato a bienes de consumo intensivos en trabajo, además de la mayor demanda por productos en los cuales Chile tiene ventajas comparativas, sugiere que las oportunidades para los productores y consumidores nacionales son inmensas. Los principales productos de exportación de China son bastante distintos de los productos en los cuales Chile tiene ventajas comparativas - salvo algunas excepciones-, por lo que la competencia en terceros mercados es bastante limitada. Además, los principales productos de exportación de China tanto a Chile como al resto del mundo corresponden a industrias en las cuales la producción doméstica es limitada, como calzado, vestuario, artículos electrónicos, por lo que el beneficio para los consumidores compensa ampliamente los posibles efectos negativos en los productores de esos bienes.

Resulta interesante notar que mientras la estructura de importaciones chilenas de productos chinos es muy parecida a la estructura general de exportaciones chinas, no sucede lo mismo con las exportaciones de productos chilenos a China. Estas últimas están altamente concentradas en tres productos - cobre, pulpa de madera y harina de pescado—, lo que sugiere que el acceso a los mercados chinos es limitado. Dado que China no es un importante exportador de los productos que Chile exporta a terceros países, la baja penetración de productos chilenos, como productos agrícolas, productos químicos y algunos productos manufacturados, se explica por las barreras arancelarias y especialmente las no arancelarias para acceder al mercado chino. En este sentido, es evidente que el mercado chileno es mucho más abierto a los productos chinos que viceversa. Aquí radican las principales ganancias que un TLC con China puede significar para Chile.

Los posible efectos de un TLC sobre los flujos de inversión extranjera hacia Chile deben ser analizados cuidadosamente. En mi opinión, y sin contar con un estudio detallado, las mayores posibilidades de inversión extranjera radican en sectores de materias primas, como cobre o madera, donde China es deficitaria y pretende asegurar cierto grado de suministro. 
No serían esperables grandes flujos de inversión extranjera que sirvan como plataforma exportadora de productores chinos hacia terceros países, ya que son pocas las ventajas de costos de puede ofrecer Chile en bienes en los cuales China es un importante exportador. Más aún, gran parte de las exportaciones de China son de empresas extranjeras que producen en China y que exportan al resto del mundo. Para estas empresas multinacionales, un TLC de Chile con China no debiera representar un incentivo adicional para invertir en Chile, a no ser que les permita un acceso preferencial a los mercados chinos por la vía de invertir en Chile para exportar a China.

Un párrafo especial merece el alto impacto que el crecimiento de China ha tenido en el mercado mundial de cobre. De seguir creciendo a tasas cercanas a los dos dígitos, es esperable que se materialicen importantes inversiones nacionales y extranjeras en cobre, con la consiguiente apreciación del tipo de cambio real. Es evidente que un precio del cobre cercano a 130 centavos de dólar la libra no es sostenible, por lo que los aumentos en la oferta mundial de cobre debieran llevar el precio a su equilibrio de largo plazo. Es importante, por lo tanto, aprovechar esta oportunidad para generar un ambiente de inversión en Chile que facilite y dé estabilidad a los inversionistas extranjeros.

\section{REFERENCIAS}

Banco Central de Chile: Indicadores de Comercio Exterior. Varios números.

Banco Central de Chile, Comisión Nacional de Distorsiones en el Precio de las Mercaderías Importadas: Antecedentes Estadísticos 1981-2002, 2003.

Chow, Gregory: China's Economic Transformation. Blackwell Publishers, 2002.

Claro, Sebastián: “25 Años de Reformas Económicas en China: 1978-2003”. En Estudios Públicos, 91, invierno, 2003.

Comisión Chilena del Cobre (Cochilco): Estadísticas del Cobre y otros Minerales: 1993-2002. (Anuario). Vigésima segunda edición, julio 2003.

Contreras, G., y P. Meller: "La Competitividad de las Exportaciones Chinas en los Mercados de Estados Unidos y Japón”. Documento de Trabajo $N^{\circ}$ 152, Centro de Economía Aplicada, Universidad de Chile, 2002.

Corden, Max: "Booming Sector and Dutch Disease Economics". Oxford Economic Papers, 1984.

Engel, E., y P. Meller, eds.: External Shocks and Stabilization Mechanisms. Washington D.C.: Interamerican Development Bank, distribuido por The John Hopkins University Press, 1993.

European Communities: China's Accession to TWO: Tariff Schedule, 2001. www.europa.ev.int Jofré, J., R. Lüders y G. Wagner: "Economía Chilena: 1810-1995. Cuentas Fiscales". Documento de Trabajo $\mathrm{N}^{\circ} 188$, Instituto de Economía, Pontificia Universidad Católica de Chile, 1998. 
Finger, J. M., y M. E. Kreinin: “A Measure of 'Export Similarity’ and Its Possible Uses”. En Economic Journal, 89 (1979).

Freeman, R.: “Are Our Wages set in Beijing?" En Journal of Economic Perspectives, 9 (3), 1995.

Lardy, N.: Integrating China into the Global Economy. Brookings Institution Press, 2002.

Larraín, F., J. Sachs, y A. Warner: "A Structural Analysis of Chile's Long Term Growth: History, Prospects and Policy Implications". Documento preparado para el Gobierno de Chile, 2000.

Lederman, D., y W. Maloney: "Open Questions about the Link between Natural Resources and Economic Growth: Sachs and Warner Revisited". Mimeo, World Bank, Washington D. C., 2001.

Manzano, O., y R. Rigobón: "Resource Curse or Debt Overhang". NBER Working Paper 8390, 2001.

Matsuyama, K.: "Agricultural Productivity, Comparative Advantage, and Economic Growth". En Journal of Economic Theory, 58 (1992).

Meller, P.: "El Cobre Chileno y la Política Minera". En P. Meller (ed.), Dilemas y Debates en torno al Cobre. Santiago: Dolmen-CEA, 2000.

Morandé, F., y J. Quiroz: "The Koper Boom in the Chilean Economy: What Should We Expect?". Dirección de Estudios DE/16/96, COCHILCO, Santiago, 1996.

Nauhgton, B.: "China's Emergence and Prospects as a Trading Nation". Brookings Papers on Economic Activity 0 (2), 1996.

Organización Mundial de Comercio (OMC): "Technical Note on the Accession Process: Note by the Secretariat", Doc. 03-2861, 2003.

Sachs, J., y A. Warner: "Sources of Slow Growth in African Economies". En Journal of African Economies, 6(3), 1997.

Schott, Peter: "The Relative Competitiveness of China's Exports to the United States vis a vis Other Countries in Asia, the Caribbean, Latin America and the OECD”. Mimeo, Yale School of Management, 2004.

USDA Foreign Agricultural Service: "Solid Wood Products". GAIN 2003 Annual Report on People's Republic of China.

U.S International Trade Commission. www.dataweb.usitc.gov

World Bureau of Metal Statistics: World Metal Statistics Yearbook, 2003. 